Camilla Magalhães de Almeida

\title{
Modelo de Reformatação de Contratos de Energia Hídrica Para Mitigação do Risco Hidrológico de Hidrelétricas
}

Dissertação apresentada ao Programa de PósGraduação em Administração de Empresas como requisito parcial para obtenção do grau de Mestre em Administração de Empresas.

Orientador: Prof. Leonardo Lima Gomes 
Camilla Magalhães de Almeida

\title{
Modelo de Reformatação de Contratos de Energia Hídrica Para Mitigação do Risco Hidrológico de Hidrelétricas
}

Dissertação apresentada como requisito parcial para obtenção do grau de Mestre pelo Programa de PósGraduação em Administração de Empresas do Departamento de Administração da PUC-Rio. Aprovada pela Comissão Examinadora abaixo assinada.

\author{
Prof. Leonardo Lima Gomes \\ Orientador \\ Departamento de Administração - PUC-Rio
}

Prof. Luiz Eduardo Teixeira Brandão Departamento de Administração - PUC-Rio

Profa. Marta Corrêa Dalbem

Pesquisadora Autônoma

Profa. Mônica Herz Vice-Decana de Pós-Graduação do CCS - PUC-Rio

Rio de Janeiro, 7 de abril de 2017. 
Todos os direitos reservados. É proibida a reprodução total ou parcial do trabalho sem autorização da autora, do orientador e da universidade.

\section{Camilla Magalhães de Almeida}

Graduou-se em Ciências Econômicas pela Fundação Getulio Vargas (FGV) em 2013, tendo concluído o MBA em Finanças Corporativas na mesma instituição em 2015. Aluna de mestrado da PUC-Rio de Administração em Empresas com ênfase em Finanças desde março de 2015.

Ficha Catalográfica

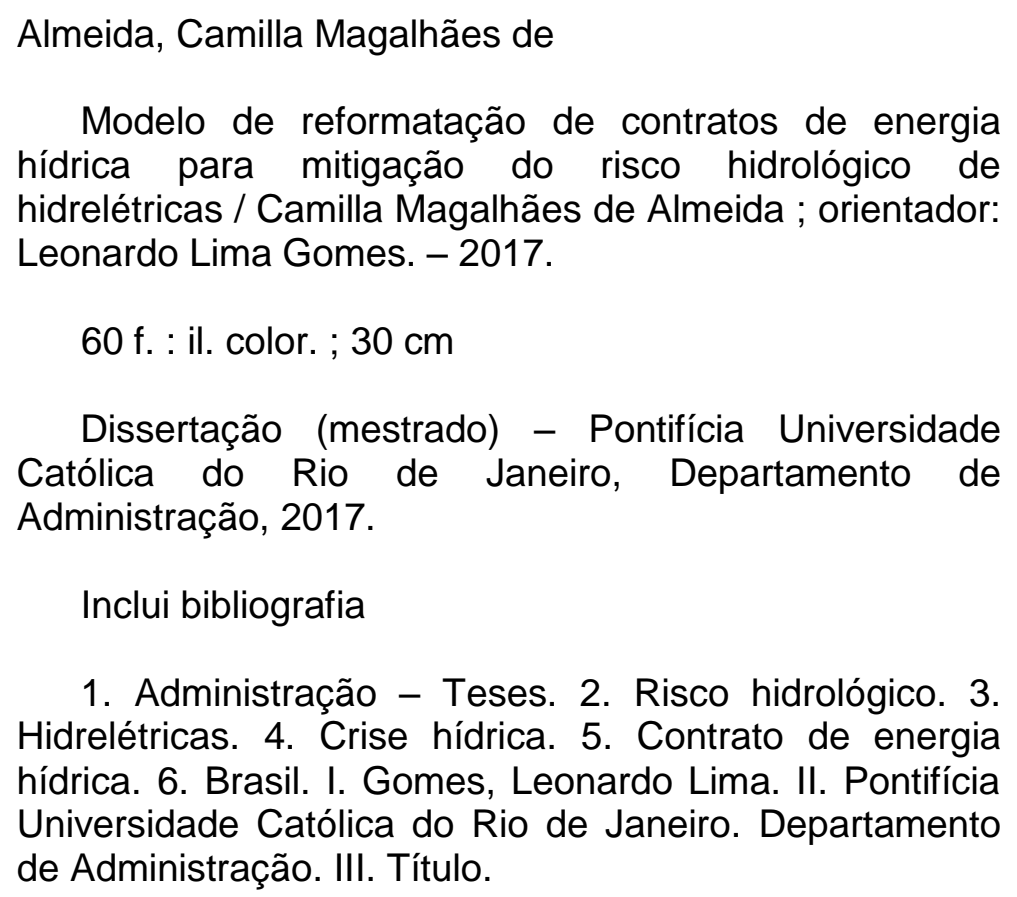

1. Administração - Teses. 2. Risco hidrológico. 3. Hidrelétricas. 4. Crise hídrica. 5. Contrato de energia hídrica. 6. Brasil. I. Gomes, Leonardo Lima. II. Pontifícia Universidade Católica do Rio de Janeiro. Departamento de Administração. III. Título. 


\section{Agradecimentos}

À minha família, pelo incentivo, carinho e suporte.

Ao meu orientador, Leonardo Lima Gomes, por todo o apoio e orientação.

Ao apoio da CAPES e da FAPERJ, pelas bolsas concedidas para que eu pudesse me dedicar exclusivamente ao mestrado.

Ao Núcleo de Pesquisa em Energia e Infraestrutura (NUPEI), à Queiroz Galvão Energia e ao Projeto de P\&D da ANEEL, que possibilitaram a concretização deste estudo. 


\section{Resumo}

Almeida, Camilla Magalhães de; Gomes, Leonardo Lima (Orientador). Modelo de Reformatação de Contratos de Energia Hídrica Para Mitigação do Risco Hidrológico de Hidrelétricas. Rio de Janeiro, 2017. 60p. Dissertação de Mestrado - Departamento de Administração, Pontifícia Universidade Católica do Rio de Janeiro.

Entre 2013 e 2015, os níveis dos reservatórios das hidrelétricas brasileiras foram reduzidos pelas secas que atingiram o país. Como consequência, o Operador Nacional do Sistema restringiu a geração hídrica na composição da oferta de energia, aumentando a participação de energia térmica no suprimento da demanda. A restrição da geração hídrica, no entanto, impossibilitou os geradores hidrelétricos de cumprirem seus contratos de venda com a geração própria, forçando-os a comprar energia no mercado de curto prazo e acumular prejuízos. A crise hídrica evidenciou a exposição dos geradores hidrelétricos aos riscos hidrológicos, consequência da modalidade contratual praticada na comercialização de energia hídrica, na qual os geradores assumem todo o risco relacionado à geração. O presente estudo apresenta uma alternativa a este modelo de contratação, de forma que a parte da geração mais exposta aos riscos hidrológicos seja vendida na modalidade que repassa os riscos ao comprador. Para que não haja alteração nos custos totais esperados do comprador com a troca de modelos, o gerador deve pagar um prêmio, refletido na diferença de preços entre as duas modalidades de venda. Os resultados mostraram ganhos em termos de equivalente de certeza e redução considerável do CVaR para o gerador em todos os cenários analisados, porém, o prêmio demonstrou significativa sensibilidade em relação a diversos fatores do modelo.

\section{Palavras-chave}

Risco Hidrológico; Hidrelétricas; Crise Hídrica; Contrato de Energia Hídrica; Brasil. 


\section{Abstract}

Almeida, Camilla Magalhães de; Gomes, Leonardo Lima (Advisor). Reformatting Model for Hydroelectric Contracts in Order to Mitigate Hydrological Risks for Hydro Power Generators. Rio de Janeiro, 2017. 60p. Dissertação de Mestrado - Departamento de Administração, Pontifícia Universidade Católica do Rio de Janeiro.

Between 2013 and 2015, the water levels at storage reservoirs of the Brazilian hydroelectric power plants were reduced by the droughts that impacted the country. As a consequence, the National System Operator restricted hydro power generation in its offer composition, increasing the thermal energy generation to meet the demand. However, this restriction on hydro power energy prevented suppliers from fulfilling their contracts through their own energy production, which forced them to purchase short-term-trade energy and accumulate loss. This water crisis highlighted how exposed hydro power generators are to hydrological risks, a consequence of the contractual modality practiced in this market, in which suppliers take on all of the risk associated with generating power. This study presents an alternative to this contractual model, one in which part of the hydroelectric energy is sold in a modality of contract where risks are borne by the buyer. In exchange, the hydro generator is expected to pay a premium, reflected on the price difference between the two contractual modalities and calculated in a way that would not alter the expected total costs for the buyer. The results showed gains in terms of certainty equivalent and a considerable decrease of $\mathrm{CVaR}$ for the hydro generator in all analyzed scenarios. The premium, however, showed significant sensitivity in regards to many factors of the model.

\section{Keywords}

Hydrological Risk; Hydroelectric Power Plants; Water Crisis; Hydroelectric Contract; Brazil. 


\section{Sumário}

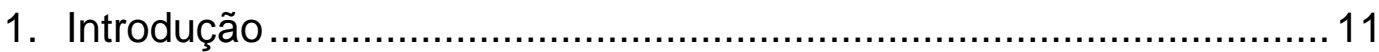

1.1. Objetivo e Proposta ............................................................. 12

1.2. Organização do Trabalho ............................................................ 13

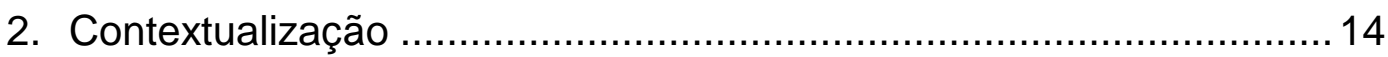

2.1. O Setor Elétrico Brasileiro (SEB) .............................................. 14

2.2. O Mecanismo de Realocação de Energia (MRE) .......................... 15

2.3. O Preço de Liquidação das Diferenças (PLD) ................................ 16

2.4. Os Ambientes de Contratação e as Modalidades de Contrato ........... 17

2.5. Desdobramentos Regulatórios ................................................... 18

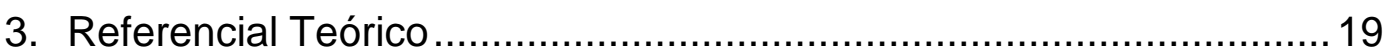

3.1. Aversão ao Risco e Equivalente de Certeza ................................... 19

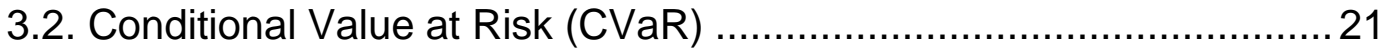

3.3. Revisão Bibliográfica ........................................................ 22

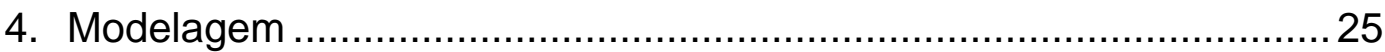

4.1. Apresentação do Modelo e Formulação Geral ............................. 25

4.1.1. Gerador Hidrelétrico ............................................................. 26

4.1.2. Compradores (Distribuidores/Consumidores) ............................2 27

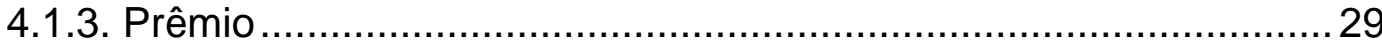

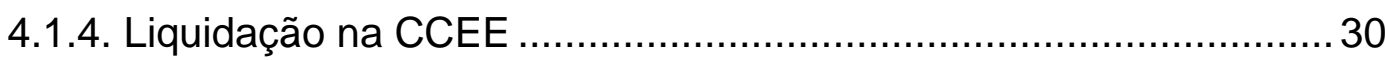

4.2. Apresentação dos Dados ...................................................... 32

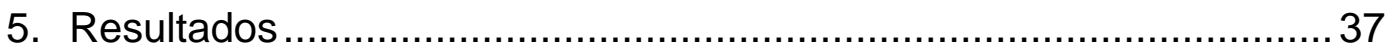

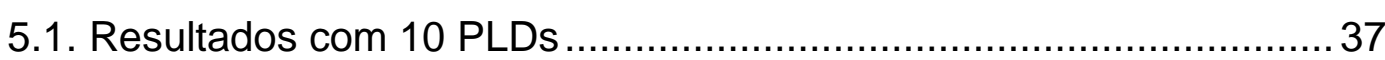

5.2. Resultados com 2.000 PLDs Mensais ........................................ 42

5.2.1. Análise de Sensibilidade ......................................................... 43

5.2.2. Equivalente de Certeza .......................................................... 46

5.2.3. Conditional Value-at-Risk (CVaR) para o Gerador ........................ 48

5.2.4. Conditional Value-at-Risk (CVaR) para o Comprador ....................5 50

6. Conclusões e Sugestões para Trabalhos Futuros .........................5 53

7. Referências bibliográficas ........................................................ 56 


\section{Lista de Figuras}

Figura 1 - Função Utilidade para cada Perfil de Risco ........................................20

Figura 2 - Ilustração do VaR de uma carteira. Fonte: Adaptado de Hull (2015).. 21

Figura 3 - Energia contratada total por tipo de contrato no modelo atual ............. 33

Figura 4 - Energia contratada total por tipo de contrato no modelo proposto ....... 34

Figura 5 - Operação e Contabilização CCEE ....................................................... 35

Figura 6 - Análise de sensibilidade do prêmio em relação à carga do sistema..... 44

Figura 7 - Análise de sensibilidade do prêmio em relação à energia da base....... 45

Figura 8 - Análise de sensibilidade do prêmio em relação ao CVU da UTE ....... 45

Figura 9 - Função Utilidade com diferentes coeficientes de aversão ao risco...... 47

Figura 10 - Ganhos de Equivalente de Certeza dos Geradores Hidrelétricos ....... 47 


\section{Lista de Tabelas}

Tabela 1 - Dados do Modelo Conceitual ................................................................. 32

Tabela 2 - Média dos Intervalos Entre Decis da Simulação de PLDs ................... 37

Tabela 3 - Operação relativa a cada Decil ......................................................... 38

Tabela 4 - Balanços contratuais nos modelos atual e proposto ............................. 39

Tabela 5 - Liquidação CCEE em milhões R $\$$ com carga de 66,5 GWmed .......... 40

Tabela 6 - Liquidação CCEE em milhões R \$ com carga de 72,3 GWmed ........... 41

Tabela 7 - Prêmio esperado considerando 10 PLDs ............................................... 41

Tabela 8 - Prêmio esperado considerando 2.000 séries mensais de PLD ............. 42

Tabela 9 - Prêmio Esperado para cada mês de 2016 ........................................... 43

Tabela 10 - Análise de CVaR para o gerador no Modelo Atual ......................... 49

Tabela 11 - Diferença na receita proveniente de contratos .................................. 49

Tabela 12 - Análise de CVaR da Liquidação da CCEE no Modelo Atual ............50

Tabela 13 - Análise de CVaR com CVU para o comprador no Modelo Atual .... 51 


\section{Lista de Siglas e Abreviaturas}

$A C L$ - Ambiente de Contratação Livre

ACR - Ambiente de Contratação Regulada

ANEEL - Agência Nacional de Energia Elétrica

CCEE - Câmara de Comercialização de Energia Elétrica

CMO - Custo Marginal de Operação

CVaR - Conditional Value at Risk (Valor em Risco Condicional)

CVU - Custo Variável Unitário

ENA - Energia Natural Afluente

EPE - Empresa de Pesquisa Energética

GWmed - Gigawatt médio

GSF - Generation Scaling Factor

$\mathrm{MWh}$ - Megawatt hora

MAE - Mercado Atacadista de Energia

MME - Ministério de Minas e Energia

MRE - Mecanismo de Realocação de Energia

ONS - Operador Nacional do Sistema Elétrico

$\mathrm{PCH}$ - Pequena Central Hidrelétrica

PDE - Plano Decenal de Expansão de Energia

PLD - Preço de Liquidação das Diferenças

SE/CO - Sudeste/Centro-Oeste

SEB - Setor Elétrico Brasileiro

SIN - Sistema Interligado Nacional

UHE - Usina Hidrelétrica de Energia

UTE - Usina Térmica de Energia

VaR - Value at Risk (Valor em Risco) 


\section{Introdução}

As usinas hidrelétricas do Sistema Elétrico Brasileiro (SEB) foram negativamente impactadas com as secas enfrentadas pelo Brasil entre 2013 e 2015. A queda nos níveis dos reservatórios motivou o Operador Nacional do Sistema Elétrico (ONS) a trocar parte da energia hídrica por outras fontes de energia no suprimento da demanda nacional, restringindo a geração das usinas hidrelétricas. A oferta interna de energia hidráulica caiu 8,6\% de 2013 a 2015, enquanto os Preços da Liquidação das Diferenças (PLD), que correspondem aos preços de curto prazo da energia (preço spot), aumentaram mais de $100 \%$ no período (EPE, 2015; 2016; CCEE, 2017).

A redução da geração hídrica causou prejuízos financeiros aos geradores hidrelétricos, que vendem sua energia em contratos por quantidade. Nesta modalidade contratual, os riscos hidrológicos são assumidos pelo gerador, que precisa comprar energia no mercado de curto prazo caso sua geração não atinja a quantidade vendida contratualmente.

As usinas hidrelétricas despachadas de forma centralizada pelo ONS pertencem ao Mecanismo de Realocação de Energia (MRE), que tem como objetivo mitigar o risco hidrológico entre os participantes. Neste mecanismo, tanto os superávits quanto os déficits de geração individuais são redistribuídos proporcionalmente entre os geradores. Portanto, em cenários de crise, o setor brasileiro de energia elétrica é afetado como um todo. Em julho e agosto de 2015, a inadimplência nas operações do mercado de curto prazo era de 56\% (CCEE, 2015).

A exposição dos geradores hidrelétricos aos cenários de secas e mudanças no planejamento do ONS, ambos fatores exógenos ao poder dos geradores, criaram uma necessidade de estudos em busca de alternativas para o atual modelo de comercialização de energia hídrica no Brasil. O modelo vigente de contratação expõe geradores e consumidores à variabilidade de geração hídrica, o que motiva 
a pesquisa por modelos que busquem minimizar os riscos enfrentados pelos agentes participantes do comércio de energia brasileiro.

\section{1.}

Objetivo e Proposta

O objetivo deste trabalho é apresentar e analisar uma alternativa ao formato atual de contratação de energia hídrica, visando reduzir a exposição dos geradores aos riscos hidrológicos, por meio de um modelo conceitual. Atualmente, em cenários de déficits de geração hídrica, os geradores hidrelétricos são obrigados a comprar energia no mercado de curto prazo para cumprir seus contratos, tornando-se expostos aos preços spot e, consequentemente, a prejuízos financeiros. Este estudo propõe uma forma de contratação de energia hídrica pela qual as hidrelétricas reduziriam suas exposições aos preços do mercado de curto prazo.

A proposta consiste em comercializar em contratos por quantidade apenas o nível de energia firme das usinas hidrelétricas, o que corresponde ao montante de energia que uma usina consegue gerar constantemente mesmo sob a maior seca já registrada no rio onde está localizada (ANEEL, 2005). O modelo propõe que a geração excedente além deste nível seja vendida em contratos por disponibilidade, nos quais o gerador não se compromete em entregar um montante prédeterminado, mas a geração real da usina. Como nesta modalidade de contrato o comprador assume os riscos hidrológicos, o modelo inclui o pagamento de um prêmio, refletido na diferença de preço entre as duas modalidades de venda, para que os custos esperados do comprador não se alterem com a troca de modelos.

No modelo proposto, o gerador passa a ter uma receita previsível, independente do seu nível de geração. Para tal, este deve aceitar uma redução na sua receita esperada proveniente de contratos de longo prazo, porém mantendo sua receita esperada inalterada quando as perdas devido às exposições ao mercado de curto prazo são consideradas. Assumindo o gerador como um agente avesso ao risco, este modelo se torna preferível em relação ao modelo atual de contratação de energia hídrica pois propõe a troca de retornos variáveis por retornos previsíveis. 


\section{2.}

\section{Organização do Trabalho}

No primeiro capítulo, foi feita uma breve contextualização do problema que motivou o tema desta dissertação e foram explicitados o objetivo e a proposta deste trabalho. A contextualização será apresentada de forma mais aprofundada no Capítulo 2, com a introdução de conceitos importantes para a compreensão do modelo apresentado. No Capítulo 3, serão apresentados o referencial teórico das metodologias utilizadas nas análises dos resultados - aversão ao risco, equivalente de certeza e Conditional Value-at-Risk (CVaR) - e uma revisão bibliográfica sobre formas de mitigação dos riscos hidrológicos de hidrelétricas.

A modelagem está detalhada no Capítulo 4, no qual também são exibidos os dados e os cenários considerados no modelo. No Capítulo 5, são apresentados os resultados, primeiro considerando apenas 10 PLDs e depois com todas as séries simuladas. Em seguida são apresentadas as análises de equivalência de certeza e CVaR para os geradores e compradores. As conclusões sobre os resultados, além de sugestões para trabalhos futuros, são feitas no Capítulo 6. 


\section{2 \\ Contextualização}

\section{1.}

\section{O Setor Elétrico Brasileiro (SEB)}

Com o objetivo de aumentar a eficiência por meio da competição, o setor elétrico brasileiro (SEB) sofreu diversas reestruturações no final dos anos 90 (Camargo, 2005). Neste período, empresas de geração e distribuição de energia elétrica foram privatizadas e foram criados o Operador Nacional do Sistema (ONS), a Agência Nacional de Energia Elétrica (ANEEL) e o Mercado Atacadista de Energia (MAE) (Pereira, Barroso \& Rosenblatt, 2004).

Após a crise energética de 2001, o SEB sofreu novas mudanças para garantir a sua expansão, marcadas pela Lei $n^{\circ} 10.848 / 2004$ (Camargo, 2005). Esta lei revisou as condições de contratação de energia no país e concedeu à Câmara de Comercialização de Energia Elétrica (CCEE) as funções de contabilização e liquidação de energia elétrica, que antes eram atribuídas ao MAE (Brasil, 2004c). Segundo Pereira, Barroso \& Rosenblatt (2004), um dos aspectos mais importantes do SEB é o fato do mercado de curto prazo de energia brasileiro não ser de fato um mercado à vista, mas um procedimento de contabilização da diferença entre a produção de energia e a quantidade contratada, o que é atualmente realizado pela CCEE.

Enquanto a CCEE é responsável pela contabilização financeira, a operação do SEB é planejada pelo ONS, que tem como principais funções coordenar e controlar a produção e transmissão de energia elétrica no Sistema Interligado Nacional (SIN), sob regulamentação e fiscalização da ANEEL (Brasil, 2004d). O SIN é formado por empresas geradoras e transmissoras de energia elétrica das cinco regiões do Brasil e cobre mais de $98 \%$ do sistema brasileiro de energia elétrica (ONS, 2016b).

Segundo o Decreto n5.081/2004, o ONS é responsável tanto pelo planejamento da operação no SIN quanto pela decisão da ordem de despacho 
centralizado da geração (Brasil, 2004a). De forma geral, para planejar o despacho centralizado, o ONS analisa os custos de geração de cada usina e a disponibilidade de recursos, visando garantir o suprimento contínuo de energia elétrica ao menor custo possível (ONS, 2016a).

\section{2. \\ O Mecanismo de Realocação de Energia (MRE)}

No despacho centralizado, os geradores de hidrelétricas não têm controle sobre a sua geração, visto que esta é determinada pelo ONS. Além disso, em usinas localizadas no mesmo rio, a operação ótima individual pode diferir da operação ótima do sistema como um todo (CCEE, 2013). Neste contexto, o Mecanismo de Realocação de Energia (MRE) foi criado com o objetivo de compartilhar os riscos hidrológicos entre as hidrelétricas participantes, abrangendo todas as usinas sujeitas ao despacho centralizado e Pequenas Centrais Hidrelétricas (PCH) que optem pela participação (CCEE, 2013). Neste mecanismo, os déficits ou excedentes de geração são redistribuídos entre as usinas participantes, de forma a mitigar as exposições individuais aos riscos hidrológicos.

O parâmetro utilizado para medir se houve déficit ou excedente de geração é a garantia física da usina, também chamada de energia assegurada, a qual corresponde ao limite máximo que uma usina pode comercializar (ANEEL, 2005). A garantia física do SIN é definida pelo Ministério de Minas e Energia (MME) e pela Empresa de Pesquisa Energética (EPE) como a "máxima quantidade de energia que este sistema pode suprir a um dado critério de garantia de suprimento", e seu cálculo é feito com base em um processo iterativo por meio de simulações da operação do sistema hidrotérmico, com a convergência determinada pela aproximação entre custo de operação médio anual e o custo marginal de expansão (MME \& EPE, 2008). Atualmente, o critério de não atendimento da garantia física é de 5\% (CCEE, 2010).

A garantia física total do SIN é rateada entre os empreendimentos que compõem o sistema, e a determinação das garantias físicas individuais das usinas hidrelétricas é feita de forma proporcional aos níveis de energia firme de cada empreendimento (MME \& EPE, 2008). No MRE, se a soma da geração real das 
usinas participantes atingir a garantia física total, o excedente das usinas superavitárias, chamado de energia secundária, é realocado de forma que todas as usinas do mecanismo recebam suas garantias físicas individuais contabilmente.

Caso a geração total seja superior à garantia física do MRE, a energia secundária do sistema é realocada de modo que todas as usinas participantes recebam parte do excedente total, proporcionalmente às garantias físicas individuais. Contudo, caso a geração total fique abaixo da garantia física do sistema, as perdas também são realocadas, afetando negativamente todas as usinas do MRE (CCEE, 2013). Neste último cenário, as usinas que já haviam vendido o montante de energia equivalente às suas garantias físicas devem recorrer ao mercado de curto prazo para cumprir seus contratos, independente dos níveis individuais de geração.

Um indicador do nível de geração em relação à garantia física é o chamado Generation Scaling Factor (GSF), ou Ajuste do MRE (ANEEL, 2015c). Este fator consiste na razão entre a geração hídrica das usinas participantes do MRE e a garantia física total do sistema. Assim, valores de GSF maiores do que 1 (ou $100 \%$ ) significam excedente de geração, enquanto valores inferiores a 1 se referem a déficits de geração. A margem de déficit considerada aceitável pelo sistema é de 5\%, isto é, um GSF de 95\% (ANEEL, 2005). Em 2014, entretanto, o GSF foi de $91 \%$ e em 2015 ficou em torno de 85\%, impedindo as hidrelétricas de entregar a energia contratada sem recorrer ao mercado de curto prazo (ANEEL, 2015c; CCEE, 2016).

\section{3.}

\section{O Preço de Liquidação das Diferenças (PLD)}

O PLD é o preço da energia no mercado de curto prazo, isto é, se houver geração ou consumo além do previsto por contratos, a liquidação é feita pela CCEE a este preço (CCEE, 2016). O PLD é determinado semanalmente pela CCEE, considerando limites mínimo e máximo definidos pela ANEEL e seu cálculo é feito com base no Custo Marginal de Operação (CMO). O CMO é calculado a partir dos modelos NEWAVE, que define as metas de geração de acordo com a demanda e custo esperado da operação, e DECOMP, que determina o despacho ótimo de geração das usinas (CCEE, 2012). 
O cálculo do PLD é feito por submercado (Norte, Nordeste, Sudeste/CentroOeste e Sul), pois considera o custo de transmissão entre essas regiões, embora desconsidere estes custos dentro de cada submercado (Souza \& Legey, 2008). Em setembro de 2014, o submercado SE/CO concentrava 55\% do total de geração e $61 \%$ do consumo total de energia elétrica (CCEE, 2014). Para o presente estudo, foram utilizados valores de PLDs simulados para o submercado SE/CO.

O PLD possui alta volatilidade de médio prazo e, em um sistema com predominância de energia hídrica como o brasileiro, este preço tende a apresentar valores mais altos em cenários de seca (Barroso et al, 2003). Como a seca faz com que o ONS reduza a geração hídrica, é em períodos de altos PLDs que os geradores hidrelétricos se tornam expostos a estes preços. Assim, em cenários de crise hídrica, os geradores precisam comprar energia a um preço geralmente superior ao preço estabelecido nos contratos bilaterais.

\section{4 . \\ Os Ambientes de Contratação e as Modalidades de Contrato}

Como parte da reestruturação do SEB, a Lei $\mathrm{n}^{\circ}$ 10.848/2004 revisou as condições das contratações nos mercados livre e regulado, enquanto o Decreto $\mathrm{n}^{\circ}$ 5.163/2004 definiu e regulamentou os ambientes de contratação de energia regulada e livre. O Ambiente de Contratação Regulada (ACR) foi definido como o segmento do mercado no qual a comercialização de energia elétrica, feita entre agentes vendedores e de distribuição, é precedida de licitação, enquanto no Ambiente de Contratação Livre (ACL) a venda e compra de energia são feitas por meio de contratos bilaterais livremente negociados (Brasil, 2004a; Brasil, 2004c).

Os contratos do ACR, chamados de Contratos de Comercialização de Energia Elétrica no Ambiente Regulado (CCEAR), podem ser realizados em dois tipos de modalidades: por quantidade e por disponibilidade. Atualmente, os contratos de comercialização de energia hídrica são feitos integralmente na modalidade quantidade, na qual os custos decorrentes dos riscos hidrológicos são assumidos pelos geradores. Se a usina hidrelétrica não gerar o montante de energia pré-determinado no contrato, é responsabilidade do gerador comprar a diferença no mercado de curto prazo para honrar o contrato. 
Na modalidade disponibilidade, comum no comércio de energia térmica, os custos decorrentes dos riscos hidrológicos são assumidos pelos compradores, sendo as exposições financeiras no mercado de curto prazo da CCEE assumidas pelos distribuidores (Brasil, 2004a). Ao contratar energia térmica nesta modalidade, os distribuidores devem pagar um valor fixo mensal ainda que a usina térmica não esteja gerando energia. Caso a usina seja acionada para despacho por comando do ONS, os distribuidores devem pagar ainda o custo variável referente à atividade da usina (Costa e Pierobon, 2008).

\section{5.}

\section{Desdobramentos Regulatórios}

Como forma de reparar as consequências dos déficits de geração hídrica, a ANEEL publicou a Resolução Normativa nº 684/2015 em dezembro de 2015, na qual foi apresentada uma proposta de repactuação do risco hidrológico para geradores hidrelétricos. O objetivo desta proposta foi oferecer uma proteção para futuras crises energéticas e amenizar os prejuízos financeiros causados pela crise hídrica em 2015. Para os geradores do Ambiente de Contratação Livre (ACL), no qual os agentes possuem maior autonomia na definição dos parâmetros dos contratos, foram oferecidos direitos de compra da chamada "energia de reserva", que foi criada com o objetivo aumentar a segurança no fornecimento de energia ao SIN (Brasil, 2008; ANEEL, 2015a).

Para os geradores do Ambiente de Contratação Regulada (ACR), no qual os contratos são padronizados e obrigatoriamente feitos por meio de leilões, foram oferecidos diversos produtos de seguros, com a proposta de transferir uma parcela dos riscos hidrológicos para o comprador em troca de pagamentos de prêmios mensais. Estes prêmios seriam pagos à Conta Centralizadora dos Recursos de Bandeiras Tarifárias (CCRBT), cujo saldo é utilizado para cobrir os custos das distribuidoras. Por meio desta proposta, as usinas puderam optar por repactuar de $89 \%$ a $100 \%$ da sua garantia física e decidir se a energia secundária seria repassada ao consumidor, o que reduziria o valor do prêmio a ser pago. Havia também uma classe de seguro com a opção de repassar os riscos de redução da garantia física ao consumidor, no qual a energia secundária também seria repassada e a proteção era obrigatoriamente de 100\% (ANEEL, 2015a; 2015b). 


\section{3 \\ Referencial Teórico}

\section{1.}

\section{Aversão ao Risco e Equivalente de Certeza}

Um agente é dito neutro ao risco quando é indiferente entre retornos fixos de valor $x$ ou retornos aleatórios cujo retorno esperado é $x$. Um agente avesso ao risco, no entanto, estaria disposto a pagar um prêmio para evitar a variabilidade dos seus retornos, protegendo-se de possíveis perdas (Damodaran, 2009). Um contrato de longo prazo é uma forma de evitar riscos sobre o preço do ativo em questão, podendo ser visto como um instrumento utilizado por agentes avessos ao risco (David et al, 2003). Barroso et al (2003) aponta a importância de contratos bilaterais pelos geradores hidrelétricos do sistema brasileiro para reduzir os riscos, dada a alta volatilidade de médio prazo do PLD.

O modelo proposto neste trabalho tem como base a premissa de que os geradores hidrelétricos possuem algum grau de aversão ao risco. Esta premissa é corroborada pelo fato destes agentes utilizarem contratos de longo prazo para vender energia hídrica, estabelecendo um preço fixo a ser recebido por todo o período do contrato e, assim, evitar a exposição à variabilidade do preço da energia. Além disso, a adesão de geradores à proposta de seguro oferecida pela ANEEL, que teve como objetivo atenuar as consequências da crise hídrica e evitar prejuízos futuros (ANEEL, 2015a), reforça a indicação de algum nível de aversão ao risco por parte dos geradores.

As preferências de um agente podem ser compreendidas por meio da teoria da utilidade de von Neumann \& Morgenstern (1947), de forma que a utilidade de um agente neutro ao risco é a mesma entre retornos previsíveis e retornos aleatórios com mesmo resultado esperado, enquanto um agente avesso ao risco apresenta maior utilidade com retornos previsíveis (Damodaran, 2009). A aversão ao risco pode ser representada por meio de um coeficiente na função utilidade, de modo que a função utilidade de um agente avesso ao risco é côncava, isto é, sua sensibilidade a perdas é superior à sua sensibilidade a lucros, como mostra a 
Figura 1. Agentes neutros a risco, no entanto, apresentam função utilidade linear, enquanto agentes propensos ao risco possuem função convexa, isto é, têm maior sensibilidade a lucros (Street, 2008).

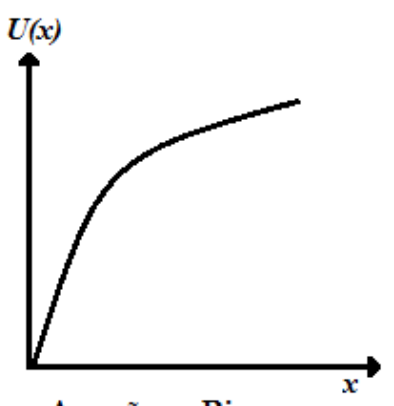

Aversão ao Risco

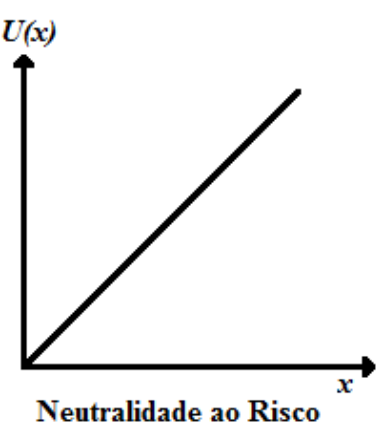

Neutralidade ao Risco

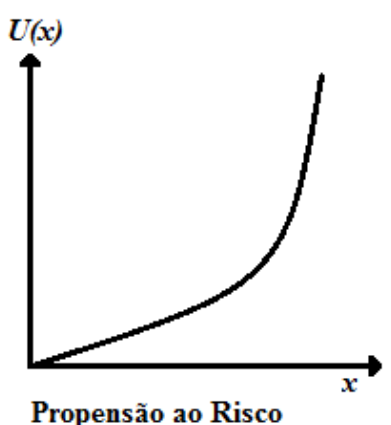

Propensão ao Risco

Figura 1 - Função Utilidade para cada Perfil de Risco

O equivalente de certeza de uma loteria é definido por Keeney \& Raiffa (1993) como o montante $\hat{x}$ que torna um agente indiferente entre este montante $\hat{x}$ e os retornos aleatórios da loteria em questão. Seja uma loteria com retornos $x_{1}, x_{2} \ldots x_{n}$, com respectivas probabilidades $p_{1}, p_{2} \ldots p_{n}$, e seja $\tilde{x}$ um retorno aleatório, a utilidade esperada desta loteria será:

$$
E[u(\tilde{x})]=\sum_{i=1}^{n} p_{i} u\left(x_{i}\right)
$$

Assim, o montante $\hat{x}$ correspondente ao equivalente certo pode ser calculado a partir das equações (2) e (3).

$$
\begin{aligned}
& u(\hat{x})=E[u(\tilde{x})] \\
& \hat{x}=u^{-1} E[u(\tilde{x})]
\end{aligned}
$$

Para agentes neutros ao risco, o valor de $\hat{x}$ será equivalente ao valor esperado da loteria, pois sua função utilidade é linear e, assim, $E[u(\tilde{x})]=u[E(\tilde{x})]$. Agentes avessos ao risco, entretanto, terão $\hat{x}$ inferior ao valor esperado da loteria, pois estes preferem retornos previsíveis a retornos aleatórios se ambos os casos têm o mesmo retorno esperado. Para torná-los indiferentes aos dois casos, o retorno esperado dos retornos aleatórios deve ser maior do que o retorno esperado dos retornos previsíveis. Quanto maior a aversão ao risco do agente, maior esta diferença deve ser para a utilidade ser a mesma nos dois casos (Street, 2008). 


\section{2.}

\section{Conditional Value at Risk (CVaR)}

A medida de risco Value at Risk (VaR) surgiu nos anos 90 como um novo método de medir o risco de mercado, destacando-se por mensurar o risco em forma de um único número em unidades monetárias (Jorion, 2003). Dado um nível de confiança $\alpha$, o VaR pode ser descrito como o nível de perda financeira que possui uma determinada probabilidade $(1-\alpha)$ de ser excedido em um período de tempo (Hull, 2015). A partir da distribuição de probabilidade do valor futuro de uma carteira $f(x)$, o VaR é o nível de perda tal que a probabilidade desta perda não ser exercida é o nível de confiança $\alpha$, descrito pela equação (4) (Jorion, 2003).

$$
\alpha=\int_{V a R_{\alpha}}^{\infty} f(x) d x
$$

Como exemplo, se o VaR de uma carteira para um dia com um nível de confiança de $95 \%$ é - $\mathrm{R} \$ 1.000,00$, significa que há uma probabilidade de $95 \%$ de que o valor da carteira não sofra uma queda maior do que mil reais em um dia e, portanto, que há uma probabilidade de $5 \%$ de que as perdas superem mil reais em um dia, como ilustra a Figura 2. Entretanto, o VaR não captura diferenças entre diferentes profundidades de perdas, podendo apresentar o mesmo valor para distribuições com curtoses distintas (Street, 2008).

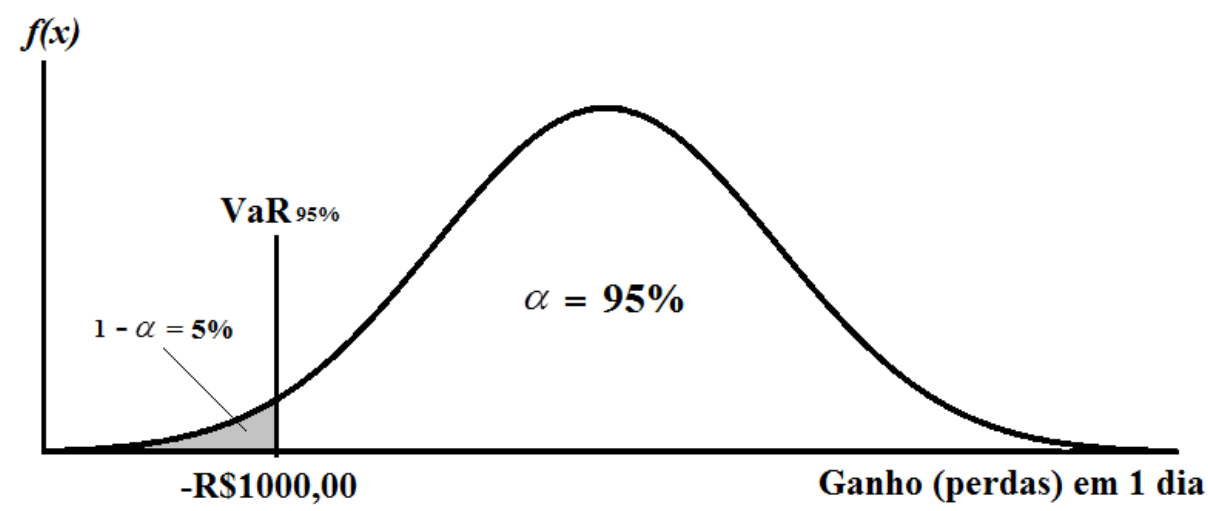

Figura 2 - Ilustração do VaR de uma carteira. Fonte: Adaptado de Hull (2015).

Santos (2013) aponta para o fato do VaR não ter a propriedade da convexidade, isto é, a soma do $\mathrm{VaR}$ de ativos individuais não é necessariamente igual ou maior ao VaR da carteira com estes ativos. A propriedade da 
convexidade é um dos axiomas definidos por Artznet et al (1999) que devem ser satisfeitos pelas medidas de risco para que estas sejam consideradas coerentes. Neste contexto, o Conditional Value at Risk (CVaR) foi proposto Rockafellar e Uryasev (2002) como uma medida de risco coerente de acordo com os axiomas definidos por Artznet et al e que captura diferentes profundidades de perdas.

Também chamado de Expected Shortfall, o CVaR é definido por Hull (2015) como a perda esperada durante um determinado período, desde que a perda seja maior do que o VaR. Assim, CVaR pode ser definido por (5) (Street, 2008).

$$
C \operatorname{VaR}=E[x \mid x \leq \operatorname{VaR}]
$$

Neste estudo, o CVaR será calculado a partir de uma simulação de 2.000 séries mensais de receitas para os geradores hidrelétricos, considerando a exposição destes ao PLD, com a finalidade de comparar o modelo vigente de contratação de energia com o modelo proposto. Neste caso, o CVaR corresponderá à média das $(1-\alpha)$ menores receitas, sendo $90 \%, 95 \%$ e $99 \%$ os níveis de confiança $\alpha$ utilizados nas análises.

\section{3. \\ Revisão Bibliográfica}

Embora a reestruturação do setor elétrico brasileiro seja recente, a busca de formas para a redução dos riscos hidrológicos enfrentados pelas hidrelétricas já foi objeto de algumas pesquisas. Castro e Brandão (2010) apontam a contratação de níveis de energia inferiores à garantia física da usina como uma estratégia que pode ser utilizada pelos geradores hidrelétricos para a redução de riscos. Porém, segundo os autores, esta descontratação de parte da garantia física não elimina o risco estrutural, pois apenas transfere a exposição ao mercado de curto prazo aos consumidores.

A sazonalização da energia comprometida em contratos, que consiste na divisão da quantidade anual de energia contratada em diferentes montantes mensais, é outra estratégia já pesquisada para a mitigação dos riscos das hidrelétricas. Sanchez (2008) apontou para a sazonalização dos contratos de energia como uma forma de reduzir a exposição do gerador ao mercado de curto 
prazo, desde que os montantes determinados sejam proporcionais à geração real. No entanto, como a geração real futura é incerta, o autor propôs a flexibilização da sazonalização, de forma que os montantes mensais possam variar dentro de margens pré-definidas nos contratos e de acordo com a geração real da usina, porém respeitando o montante anual total estabelecido em contrato. Desta forma, as divergências entre a geração real e a estabelecida em contrato para determinado mês poderiam ser compensadas dentro dos limites da margem de flexibilização, reduzindo a exposição do gerador às variações hidrológicas sazonais.

A sazonalização das garantias físicas também é abordada por Ribeiro (2012), que teve como foco de pesquisa as PCHs participantes do MRE. O estudo comparou três perfis de decisão para a sazonalização das garantias físicas: no primeiro, chamado de perfil de sazonalização direta, a decisão acompanha o histórico dos níveis de energia natural afluente $\left(\mathrm{ENA}^{1}\right)$, apresentando maiores valores entre dezembro e abril; no segundo, a sazonalização foi definida como uniforme, isto é, constante para todos os meses; no terceiro, a sazonalização é decidida de forma inversa ao histórico do ENA, sendo um espelho do primeiro perfil. Os resultados mostraram que a decisão de sazonalização direta apresentou o menor nível de risco de liquidação negativa no mercado de curto prazo em relação aos demais perfis.

No entanto, a estratégia de sazonalização é uma proteção contra variações ao longo do ano, mas não evita a exposição negativa no mercado de curto prazo quando a geração total anual é inferior ao montante vendido contratualmente. Domingues (2003) apresenta outros mecanismos de proteção aos riscos (hedging) na comercialização de energia elétrica. Para o autor, o gerenciamento de risco no setor elétrico deve ser iniciado pelos chamados "hedging físicos", que incluem a diversificação dos ativos físicos de geração de um portfólio. Neste sentido, Barroso et al (2003) analisaram a inserção de uma usina térmica em um portfólio hidrelétrico por meio de investimento ou contratação. Os resultados mostraram que a receita dos piores cenários (downside) é menor no portfólio sem a usina térmica, indicando a redução dos riscos hidrológicos com a diversificação da fonte de geração.

1 "Energia que pode ser produzida com a vazão de água de um determinado rio a um reservatório de uma usina hidrelétrica" (ABRADEE, 2017). 
Domingues (2003) também apresenta dois outros tipos de mecanismos de proteção: o "hedging nos contratos" e o "hedging financeiro". Segundo o autor, o primeiro pode ser feito por meio da decisão do nível ótimo de contratação futura, o que depende, além da relação de risco e retorno, do nível de aversão ao risco do gerador. Por fim, o hedging financeiro possibilita que o gerador se proteja da oscilação do preço da energia por meio de instrumentos de derivativos, como contratos futuros e opções. Arfux (2004), ao analisar o uso de derivativos como forma de hedging na comercialização de energia, encontrou resultados que indicam a eficácia destes instrumentos como proteção contra a volatilidade dos preços.

A proposta de repactuação dos riscos hidrológicos da ANEEL também já foram objeto de pesquisa. Brito (2016) analisou os produtos de seguro oferecidos aos geradores hidrelétricos do ACR, de forma a comparar o custo de não adesão com os custos e benefícios da adesão a cada produto. Os resultados indicaram que o valor do prêmio da classe de produtos que não repassa a energia secundária ao consumidor (classe P) não compensa os ganhos de receita com a liquidação deste excedente de energia, isto é, o prêmio mais elevado da classe P faz com que seja mais vantajoso aderir à classe de seguros que repassa a energia secundária ao consumidor (classe SP), pois esta apresentou menores perdas financeiras. A classe que repassa os riscos de redução da garantia física ao consumidor (classe SPR) não se mostrou vantajosa em cenários de redução de até $5 \%$ da garantia física, devido ao prêmio de risco elevado. Por fim, a autora apontou o nível de aversão ao risco do gerador como fator decisivo na escolha de adesão à repactuação. 


\section{4 \\ Modelagem}

\section{1.}

\section{Apresentação do Modelo e Formulação Geral}

A proposta deste estudo consiste na reformatação dos contratos de energia hídrica, de modo que uma parcela da energia proveniente de usinas hidrelétricas seja comercializada contratualmente pela modalidade disponibilidade. Neste estudo será apresentado um modelo conceitual no qual apenas a energia firme da usina é vinculada a um contrato por quantidade, enquanto a diferença entre o nível de energia firme e a garantia física da usina - parcela mais exposta aos riscos hidrológicos - é vendida por disponibilidade, isto é, o comprador assume o risco da insuficiência de geração.

Em contrapartida, a proposta inclui o pagamento de um prêmio $(\pi)$ pelo gerador para que os custos do comprador não sejam afetados pela troca de modelos. Em algumas configurações menos prováveis, nas quais a troca na forma de contratação reduz os custos do comprador, este prêmio pode ser um recebimento pelo gerador. O prêmio $\pi$ será refletido na diferença entre os preços das modalidades quantidade $\left(p^{f}\right)$ e disponibilidade $\left(p^{a}\right)$, como mostra a equação (6). Além disso, embora no contrato por disponibilidade o comprador pague pelo montante entre o nível de energia firme e o nível de garantia física, toda a energia secundária gerada também pertencerá ao comprador.

Para fins de denominação, "modelo atual” corresponderá ao modelo de comercialização vigente, isto é, o modelo no qual a energia hídrica é vendida integralmente na modalidade quantidade, e "modelo proposto" referenciará o modelo apresentado neste trabalho. Enquanto no modelo atual a quantidade de energia referente à garantia física $\left(q_{h}\right)$ é vendida integralmente ao preço $p^{f}$, no modelo proposto parte da energia será contratada por quantidade $\left(q_{h}^{f}\right)$ e outra parte será contratada por disponibilidade $\left(q^{a} h\right)(7)$, aos respectivos preços $p^{f}$ e $p^{a}$.

$$
p^{a}=p^{f}-\pi
$$




$$
q_{h}=q_{h}^{f}+q_{h}^{a}
$$

Os principais agentes deste modelo são o gerador hidrelétrico e o comprador, estes últimos incluindo tanto distribuidores quanto consumidores finais, a quem os custos são repassados por meio das tarifas. Assim, na modelagem, distribuidores e consumidores terão o mesmo papel no modelo, representando a ponta compradora dos contratos de energia. As seções seguintes detalharão os impactos de ambos os modelos nesses dois agentes, assim como o cálculo do prêmio e a visão da CCEE.

\subsection{1.}

\section{Gerador Hidrelétrico}

No modelo atual, a energia hídrica é vendida em contratos por quantidade, a um preço pré-determinado $p^{f}$. Os geradores podem comercializar contratualmente a produção de energia correspondente à sua garantia física ou com uma margem de segurança para reduzir sua exposição aos riscos hidrológicos (ANEEL, 2005). Para fins de comparação com o modelo proposto, será assumido que, no modelo atual, o gerador vende por meio de contratos o montante equivalente à sua garantia física $\left(q_{h}\right)$.

Caso a usina hidrelétrica gere um nível $h$ tal que supere o nível da garantia física, no modelo atual, o excedente de geração pode ser vendido ao $\operatorname{PLD}(p)$ como um adicional à receita. Entretanto, déficits de geração ( $h$ inferior a $\left.q_{h}\right)$ reduzem a receita do gerador, pois este cenário o obriga a comprar energia no mercado de curto prazo para entregar o total estabelecido em contrato. Assim, a receita do gerador no modelo atual $\left(R^{A}\right)$ pode ser descrita a partir da equação (8).

$$
R^{A}=p^{f} \cdot q_{h}+\left(h-q_{h}\right) p
$$

Desta forma, como $q_{h}$ e $p^{f}$ são pré-definidos em contrato, os riscos do gerador se concentram na variabilidade da sua geração $(h)$ e do PLD $(p)$. Caso a geração seja maior do que a garantia física, a exposição ao PLD é positiva, pois o gerador pode vender a energia secundária no mercado de curto prazo. Entretanto, quando a geração é menor do que a garantia física, o último termo da equação (8) assume valores negativos, expondo negativamente a receita do gerador ao PLD. 
No modelo proposto, a receita proveniente de contratos se divide em duas partes: a primeira referente ao contrato por quantidade e a segunda ao contrato por disponibilidade. Como apenas o nível de energia firme é vendido por quantidade e a geração acima deste nível é vendida por disponibilidade, o gerador não precisará comprar nem poderá vender energia no mercado de curto prazo, eliminando sua exposição ao PLD. Assim, a receita do gerador no modelo proposto $\left(R^{P}\right)$ pode ser descrita pela equação (9).

$$
R^{P}=q_{h}^{f} \cdot p^{f}+q^{a} h \cdot p^{a}
$$

Como todas as variáveis da equação (9) são pré-definidas em contratos, a receita do gerador se torna mais previsível no modelo proposto. É importante ressaltar que, caso a geração hídrica seja inferior ao nível de energia firme, o gerador terá que comprar a diferença no mercado de curto prazo para honrar o contrato por quantidade. Entretanto, como a energia firme corresponde ao o nível de energia que a usina consegue gerar mesmo sob a pior seca ocorrida no rio onde está localizada, foi assumido no modelo que a geração hídrica sempre atingirá este nível.

\subsection{2.}

\section{Comprador (Distribuidor/Consumidor)}

No modelo, o comprador representa os distribuidores e consumidores. Assim, tanto no modelo atual como no proposto, o comprador possui contratos de energia hídrica, energia térmica e energia de base $(b)$, a qual é composta por energia eólica, biomassa, nuclear e energia térmica inflexível. No modelo atual, quando há excedente de geração hídrica em relação à garantia física, o comprador deve comprar este excedente no mercado de curto prazo. Esse cenário ocorre porque o contrato por quantidade garante ao comprador apenas o nível da garantia física, sendo o excedente do gerador. Além disso, o operador do sistema planeja os níveis de geração das usinas hidrelétrica $(h)$ e térmica $(t)$ de forma que a quantidade total produzida (carga total) seja equivalente à demanda total $(d)$ esperada, como mostra a equação (10). Assim, quando há geração hídrica acima da garantia física, tal excedente deve compor a demanda do comprador, que por sua vez deve comprar essa energia secundária do gerador hidrelétrico. 


$$
E[h+t+b]=E[d]
$$

Déficits de geração hídrica, no entanto, significam um aumento na participação de outras fontes de energia para suprir a demanda. Em ambos os modelos, a restrição hídrica é compensada pela geração térmica, que já pertence ao comprador devido ao contrato de energia térmica por disponibilidade. Entretanto, o gerador hidrelétrico precisa entregar o montante acordado no contrato por quantidade, mesmo com a demanda do comprador já suprida devido ao aumento da geração térmica. Assim, nesse cenário, o gerador precisa comprar energia para honrar seu contrato enquanto o comprador possui um excedente de energia para vender no mercado de curto prazo ao PLD.

O contrato dos compradores com a usina térmica é feito na modalidade disponibilidade, isto é, o comprador tem direito a toda a geração de energia térmica da usina. Entretanto, diferente do contrato por quantidade, o gerador da usina térmica não tem obrigação de entregar um montante específico de energia. O comprador paga um valor fixo por mês pela disponibilidade da energia e, quando há geração, o comprador recebe a energia e deve pagar o custo variável unitário (CVU) referente ao funcionamento da usina termelétrica. Há também uma parte da energia térmica que é inflexível, isto é, tem geração constante e não pode ser desligada. Por não ser flexível, esta parte não será considerada no contrato por disponibilidade e entrará no modelo como energia de base, a qual também inclui energia eólica, nuclear e proveniente de biomassa, e cuja geração será fixa no modelo.

Os custos totais do comprador no modelo atual $\left(c^{A} c\right)$, portanto, podem ser divididos em uma parte fixa e outra variável. Na parte fixa, estão os custos com o contrato de energia hídrica $\left(c_{h}^{A}\right)$, o custo fixo com o contrato de energia térmica $\left(c_{t}\right)$ e os custos com a energia de base $\left(c_{b}\right)$. A parte variável depende da geração hídrica: quando há geração acima da garantia física, o comprador deve comprar este excedente ao PLD ( $p)$; quando há déficit, é necessário pagar o CVU da usina térmica multiplicado pela capacidade instalada desta. Neste último cenário, o comprador também se torna positivamente exposto ao PLD, o que reduz seus custos totais no modelo atual.

Desta forma, os custos totais do comprador podem ser descritos por meio da equação (11), onde $b$ é a quantidade de energia de base, $t$ é a geração de energia 
térmica, $d$ é a demanda (ou carga total) e $c_{c v u}$ é o valor do CVU multiplicado pela capacidade instalada da usina caso o valor do PLD esteja acima do CVU e zero caso contrário. Como os custos fixos com o contrato de energia térmica e com a energia de base não são afetados na troca de modelos, dado que são gastos adicionais fixos sem relação de dependência com os demais fatores, estes custos não serão considerados na modelagem dos dados. Entretanto, o valor do CVU é essencial para a decisão do operador do sistema, pois se este custo for inferior ao PLD, as térmicas serão acionadas. A equação (12) descreve o custo do comprador com o contrato de energia hídrica no modelo atual $\left(c^{A}\right)$, que consiste na quantidade total comprada por contrato $\left(q_{h}\right)$ ao preço do contrato por quantidade $\left(p^{f}\right)$.

$$
\begin{gathered}
c^{A}=c^{A}{ }_{h}+c_{t}+c_{b}-\left(q_{h}+b+t-d\right) \cdot p+c_{c v u} \\
c^{A}{ }_{h}=p^{f} \cdot q_{h}
\end{gathered}
$$

No modelo proposto, o comprador perderá a exposição ao PLD e o custo com a energia hídrica será alterado. Como agora este tipo de energia é vendido em dois contratos de modalidades diferentes, o comprador pagará o preço por quantidade $\left(p^{f}\right)$ apenas no montante de energia firme da usina $\left(q^{f} h\right)$ e, no restante $\left(q^{a} h\right)$, o preço pago será o definido para a venda de energia por disponibilidade $\left(p^{a}\right)$. A equação (13) representa os custos totais do comprador no modelo proposto $\left(c^{p}\right)$, enquanto a equação (14) descreve o custo do comprador com a energia hídrica neste modelo $\left(c^{p}{ }_{h}\right)$.

$$
\begin{aligned}
& c^{p}=c^{p}{ }_{h}+c_{t}+c_{b}+c_{c v u} \\
& c^{p}{ }_{h}=q^{f}{ }_{h} \cdot p^{f}+q^{a}{ }_{h} \cdot p^{a}
\end{aligned}
$$

No modelo proposto, o prêmio $(\pi)$ é calculado de forma a manter os custos esperados do comprador inalterados, isto é, $\mathrm{E}\left[c^{A}\right]=\mathrm{E}\left[c^{p}\right]$.

\subsection{3.}

\section{Prêmio}

O prêmio $(\pi)$ é refletido na diferença entre os preços a energia hídrica por quantidade $\left(p^{f}\right)$ e por disponibilidade $\left(p^{a}\right)$ e é calculado de forma que os custos 
esperados do comprador não se alterem na troca de modelos. Assim, a partir das equações (11) e (13), o prêmio será tal que:

$$
E\left[c^{A}{ }_{h}+c_{t}+c_{b}-\left(q_{h}+b+t-d\right) \cdot p+c_{c v u}\right]=E\left[c^{p}{ }_{h}+c_{t}+c_{b}+c_{c v u}\right]
$$

Utilizando as equações (6), (12) e (14), a equação (15) pode ser desenvolvida até a equação (16), que descreve o cálculo do prêmio.

$$
\begin{aligned}
& E\left[c^{A}{ }_{h}-\left(q_{h}+b+t-d\right) \cdot p\right]=E\left[c^{p_{h}}\right] \\
& E\left[p^{f} \cdot q_{h}-\left(q_{h}+b+t-d\right) \cdot p\right]=E\left[q^{f} \cdot p^{f}+q^{a} h \cdot p^{a}\right] \\
& -E\left[\left(q_{h}+b+t-d\right) \cdot p\right]=E\left[q_{h}^{f} \cdot p^{f}+q^{a} h \cdot p^{a}\right]-E\left[p^{f} \cdot q_{h}\right] \\
& -E\left[\left(q_{h}+b+t-d\right) \cdot p\right]=E\left[\left(q_{h}^{f} \cdot p^{f}+q^{a} \cdot p^{a}-p^{f} \cdot q_{h}\right)\right] \\
& -E\left[\left(q_{h}+b+t-d\right) \cdot p\right]=E\left[\left(p^{f}\left(q_{h}^{f}-q_{h}\right)+q_{h \cdot}^{a} \cdot p^{a}\right]\right. \\
& -E\left[\left(q_{h}+b+t-d\right) \cdot p\right]=E\left[\left(p^{f}\left(-q^{a} h\right)+q^{a} h \cdot p^{a}\right]\right. \\
& -E\left[\left(q_{h}+b+t-d\right) \cdot p\right]=E\left[\left(q^{a} h\left(p^{a}-p^{f}\right)\right]\right. \\
& -E\left[\left(q_{h}+b+t-d\right) \cdot p\right]=E\left[\left(q^{a} h(-\pi)\right]\right. \\
& \pi=E\left[\left(q_{h}+b+t-d\right) \cdot p\right] / E\left[q^{a}{ }^{a}\right]
\end{aligned}
$$

Assim, para que os custos esperados do comprador não se alterem na troca de modelos, o valor do prêmio deve corresponder à exposição esperada do comprador ao PLD dividida pelo montante de energia vendido por disponibilidade.

\subsection{4.}

\section{Liquidação na CCEE}

A CCEE é a câmara responsável por contabilizar e liquidar as compras e vendas de energia elétrica (Brasil, 2004c). A liquidação que ocorre na CCEE corresponde à diferença entre a energia comprada e a demandada. No modelo, a geração total é sempre equivalente à demanda, o que difere é o nível de geração em relação ao montante de energia estabelecido em contratos. Quando o montante contratado é maior do que a geração, significa que o comprador pode vender o excedente de energia no mercado de curto prazo. Este é o cenário no qual o 
comprador fica positivamente exposto ao PLD e os geradores não conseguem gerar o estabelecido em contrato, precisando comprar energia para honrar seus contratos.

Quando a energia demandada é maior do que a comprada, significa que há um excedente na geração hídrica que não foi contratada pelo comprador. Assim, este precisa comprar energia no mercado de curto prazo e o gerador fica positivamente exposto ao PLD. Desta forma, a liquidação da CCEE $(L)$ corresponde à exposição dos compradores ao PLD, e esta liquidação com o sinal inverso corresponde à exposição do gerador. Como o total de energia comprada equivale à soma da quantidade estabelecida no contrato de energia hídrica $\left(q_{h}\right)$ com a quantidade já comprada de energia de base $(b)$ e a geração das térmicas $(t)$, a liquidação da CCEE no modelo atual $\left(L^{A}\right)$ pode ser calculada pela equação (17), onde $d$ é a quantidade demandada e $p$ o valor do PLD.

$$
L^{A}=\left(q_{h}+b+t-d\right) \cdot p
$$

Assim, quando a liquidação da CCEE é positiva, o comprador está reduzindo seus custos com a venda de energia; quando é negativa, este precisa comprar o excedente de energia hídrica do gerador, ao PLD.

No modelo proposto, entretanto, a quantidade comprada de energia hídrica se dividirá entre os contratos por quantidade e disponibilidade. Como a entrega de energia do contrato por disponibilidade equivale à geração hídrica acima do nível de energia firme, incluindo a energia secundária, a liquidação da CCEE no modelo proposto $\left(L^{P}\right)$ pode ser descrita pela equação (18).

$$
L^{p}=(h+b+t-d) \cdot p
$$

Contudo, como o operador do sistema planeja os níveis de geração de cada fonte de forma que o nível gerado seja equivalente à demanda (Equação 10), O valor esperado para a liquidação da CCEE no modelo proposto é, portanto, zero, como mostra a equação (19).

$$
E[(h+b+t-d) \cdot p]=0=E\left[L^{P}\right]
$$

Desta forma, os riscos hidrológicos do gerador são reduzidos e a liquidação do comprador, positiva ou negativa, também é anulada. 


\section{2.}

\section{Apresentação dos Dados}

No modelo, foi considerada uma configuração na qual há apenas uma usina hidrelétrica (UHE) e uma usina térmica (UTE). Ainda que trabalhando com duas usinas, os dados utilizados para carga, capacidades instaladas, garantias físicas e energia de base são baseados em dados e projeções reais.

A Tabela 1 mostra os dados utilizados no modelo com suas respectivas fontes. A UHE do modelo possui 96,3 GWmed de capacidade instalada e 53,2 GWmed de garantia física, e seu contrato foi feito por $130 \mathrm{R} \$ / \mathrm{MWh}$, considerando a sua garantia física como quantidade vendida em contrato. A UTE, por sua vez, possui 17,7 GWmed de capacidade instalada e 12,2 GWmed de garantia física, e seu CVU é de 155 R\$MWh.

Tabela 1 - Dados do Modelo Conceitual

\begin{tabular}{lcl}
\hline Variável & GWmed & Fonte \\
\hline Carga 2016 PDE 2024 & 66,5 & EPE - (PDE 2015-2024) - jan/16 \\
Carga 2016 PDE 2022 & 72,3 & EPE - (PDE 2013-2022) - jan/14 \\
Capacidade Instalada UHEs & 96,3 & EPE - (PDE 2015-2024) - jan/16 \\
Garantia Física UHEs & 53,2 & CCEE - Relatório de Mercado - jan/16 \\
Capacidade Instalada UTEs* & 17,7 & ONS - Programa Mensal de Operação - dez/15 \\
$\quad$ Parcela Flexível & 15,0 & ONS - Programa Mensal de Operação - dez/15 \\
$\quad 2,7$ & ONS - Programa Mensal de Operação - dez/15 \\
Parantia Física UTEs & 12,2 & MME - Boletim de Monitoramento do SEB - fev/16 \\
$\quad$ Parcela Flexível & 9,5 & MME - Boletim de Monitoramento do SEB - fev/16 \\
$\quad$ Parcela Inflexível & 2,7 & ONS - Programa Mensal de Operação (PMO) - dez/15 \\
Capacidade Instalada Nuclear* & 1,8 & ONS - Programa Mensal de Operação (PMO) - dez/15 \\
Garantia Física Eólicas & 3,2 & MME - Boletim de Monitoramento do SEB (BMS) - \\
Garantia Física Biomassa & 3,1 & MME - Boletim de Monitoramento do SEB (BMS) - \\
Energia na Base** & 10,8 & PMO e BMS - dez/15 e fev/16 \\
\hline Balanço GF 2016 PDE 2024 & 7,0 & 10,5\% de sobrecontratação \\
Balanço GF 2016 PDE 2022 & 1,2 & $1,7 \%$ de sobrecontratação \\
\hline
\end{tabular}

* Capacidade Instalada Líquida de Indisponibilidades programada e forçada ** Soma das parcelas UTE Inflexível, Nuclear, Eólicas e Biomassa

A carga total utilizada é de 66,5 GWmed, número projetado em 2015 para 2016 pela EPE por meio do Plano Decenal de Expansão de Energia 2024 (PDE 2024), publicado em dezembro de 2015. Este número, entretanto, reflete uma queda no crescimento da demanda por energia, consequência da crise econômica 
brasileira. Assim, paralelamente, serão apresentados também os resultados finais calculados para uma carga de 72,3 GWmed, número projetado em 2013 para 2016 pelo PDE 2022 e que, por ter sido projetado anteriormente à crise econômica, possivelmente seria mais próximo do número real em um cenário econômico estável (MME \& EPE, 2013; 2015).

Como 2,7 GWmed da garantia física e da capacidade instalada da UTE correspondem à parcela inflexível, significando geração ininterrupta, esta parcela foi incluída na energia de base do modelo e foi chamado de "Contrato Disponibilidade UTE" apenas a parte flexível (9,5 GWmed), que pode ser desligada. No entanto, caso a geração térmica da parcela flexível seja superior à garantia física de 9,5 GWmed, podendo atingir capacidade instalada flexível de 15GWmed, o excedente também pertencerá ao comprador.

A Figura 3 mostra a estrutura de contratação do modelo atual. A soma do contrato da usina hidrelétrica de 53,2 GWmed, a parte flexível do contrato por disponibilidade da usina térmica de 9,5 GWmed e 10,8 GWmed de energia de base já contratada resulta em 73,5 GWmed, total contratado no modelo.

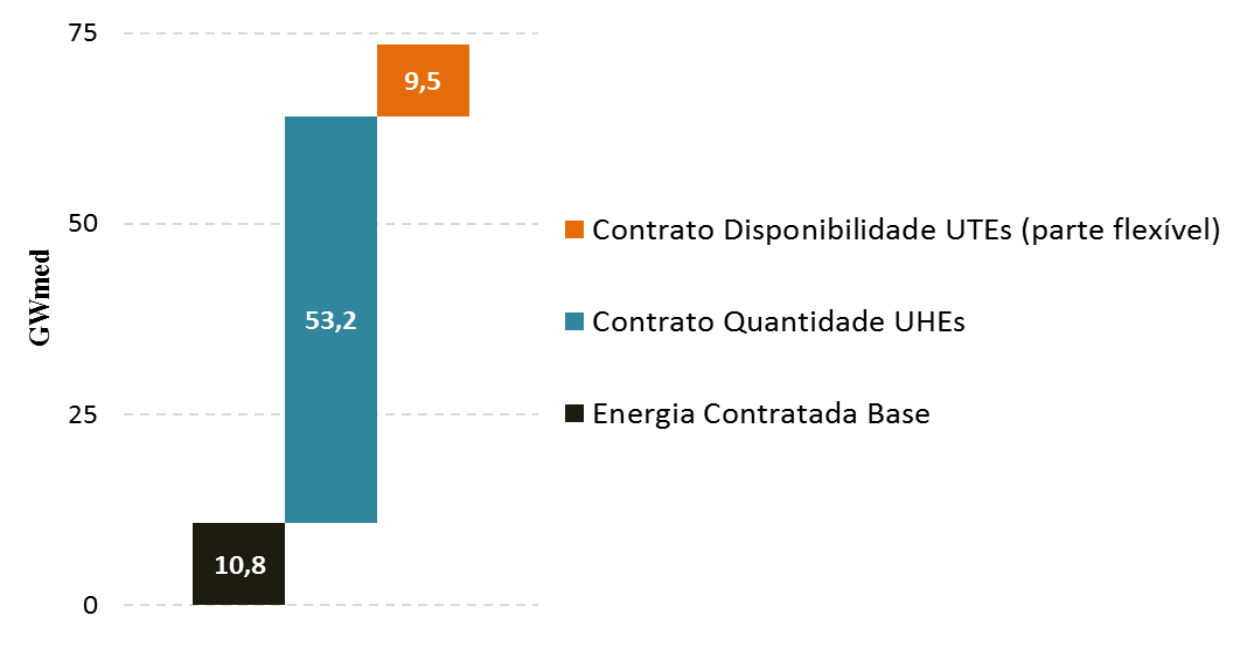

Figura 3 - Energia contratada total por tipo de contrato no modelo atual

Comparando com a carga de 66,5 GWmed, verifica-se uma sobrecontratação de 10,5\%, reflexo de uma queda de demanda não esperada por energia. Entretanto, a comparação com a carga de 72,3 GWmed, projetada em 2013 para 2016, mostra uma sobrecontratação de 1,7\%. Ilustrando os balanços de energia, a Figura 4 é referente ao modelo conceitual analisado, no qual apenas a energia firme da UHE, $40 \mathrm{GWmed}$, é contratada por quantidade, enquanto os 13,2 
GWmed restantes da garantia física estão em um contrato por disponibilidade com a UHE.

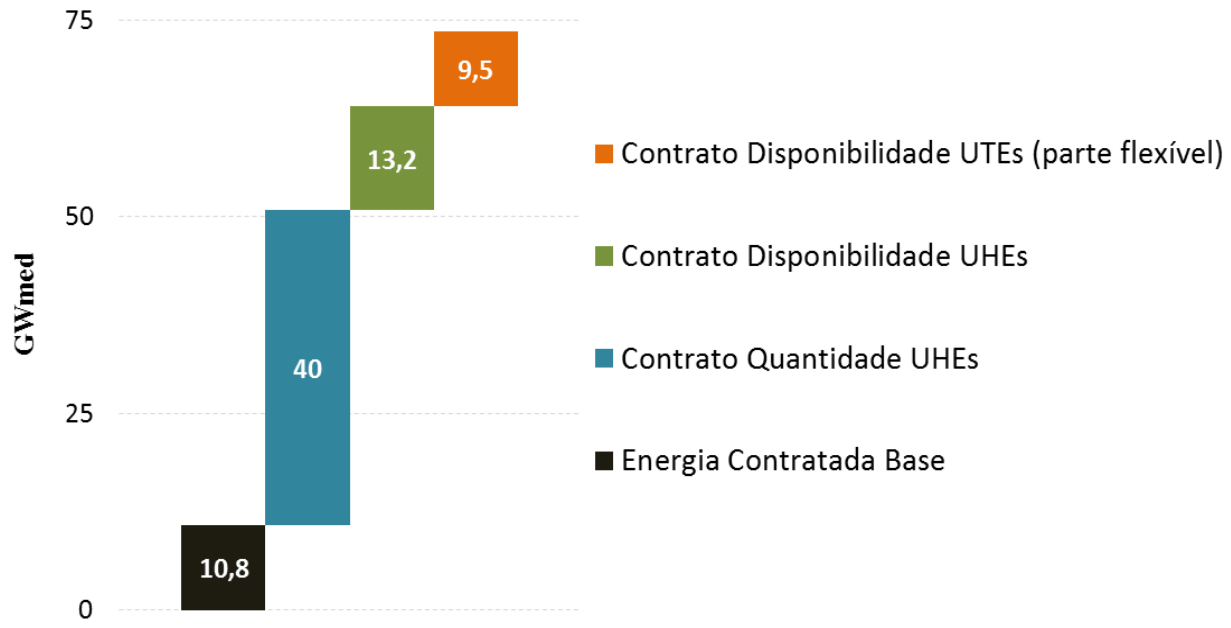

Figura 4 - Energia contratada total por tipo de contrato no modelo proposto

Para a análise do modelo, serão considerados dois cenários de operação: no primeiro, chamado "cenário restritivo", o PLD é superior ao CVU da usina térmica; no segundo, chamado "cenário folga", o PLD é inferior ao CVU. No cenário restritivo, a UTE é acionada por se tornar mais barata em relação à energia hídrica, gerando 15 GWmed de energia térmica - parte flexível de sua capacidade instalada - e fazendo com que a UHE gere somente 40,7 GWmed para, junto aos 10,8 GWmed da energia de base, somar a carga total de 66,5 GWmed (Figura 5). Em contrapartida, no cenário folga, a parcela flexível da UTE não é gerada e a UHE gera 55,7 GWmed para completar a carga demandada.

A liquidação que ocorre na CCEE corresponde à diferença entre a energia comprada e a energia demandada, representando a visão do comprador: se a energia comprada for maior do que a demandada, o comprador possui energia excedente e a liquidação apresenta saldo positivo. Por outro lado, se a energia comprada for inferior à demandada, a liquidação é negativa, significando a necessidade do comprador de comprar de energia no mercado de curto prazo para suprir a demanda. A Figura 5 mostra as diferenças na contabilização da CCEE entre o modelo atual e o modelo conceitual proposto, diante destes dois cenários, restritivo e folga. 

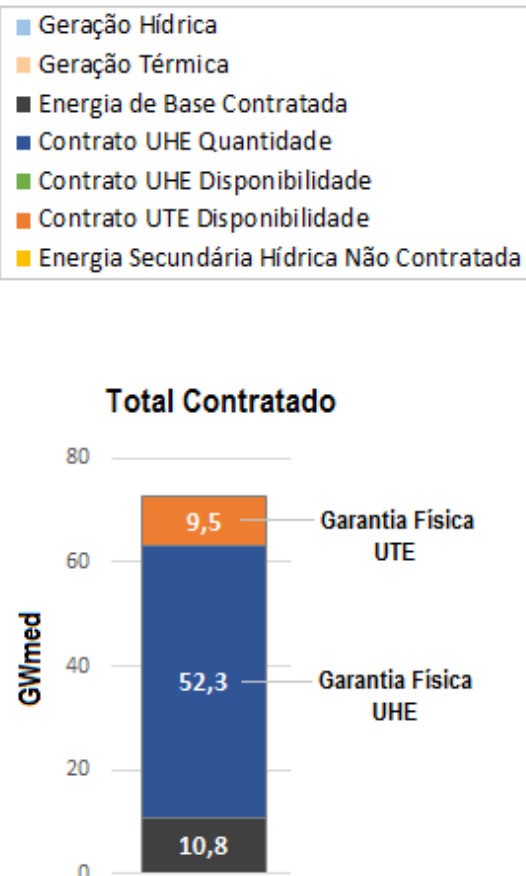

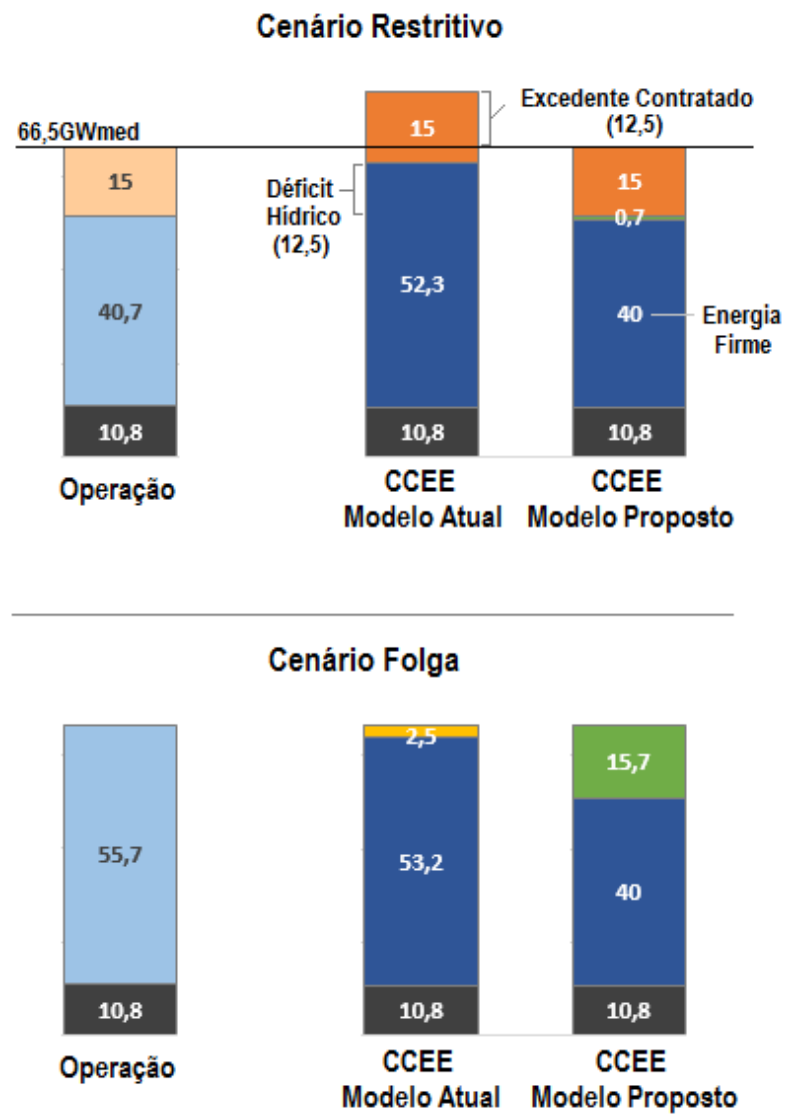

Figura 5 - Operação e Contabilização CCEE

No cenário restritivo, nas regras de contratação atuais, observa-se que a liquidação na CCEE ficaria com 12,5 GWmed além da carga contratada. Isto ocorre porque, embora a geração hídrica tenha sido de 40,7 GWmed, o contrato é de 53,2 GWmed, o que faz a hidrelétrica comprar 12,5 GWmed no mercado de curto prazo para cumprir este contrato. No modelo proposto, entretanto, não há esta sobra, pois os 12,5 GWmed que não foram gerados pela hidrelétrica estão contratados por disponibilidade, isto é, o gerador só precisa entregar a geração efetiva. O comprador, neste último caso, recebe toda a energia demandada por já possuir o contrato de disponibilidade com a UTE, mas precisa pagar o CVU por esta energia.

No cenário folga, a geração hídrica é de 55,7 GWmed, o que somado à energia de base cobre a carga contratada e, portanto, as usinas térmicas não são acionadas. No modelo proposto, o contrato por disponibilidade faz com que toda a geração hídrica acima da garantia física - 2,5 GWmed - também seja do comprador, enquanto no modelo atual este precisa comprar a energia secundária no mercado de curto prazo para suprir sua demanda. 
No modelo atual, a liquidação na CCEE é positiva no cenário restritivo e negativa no cenário folga, isto é, o comprador fica negativamente exposto ao PLD neste último cenário, enquanto o gerador hidrelétrico sofre esta exposição negativa no cenário restritivo. No modelo proposto, entretanto, as exposições dos dois agentes ao PLD em ambos os cenários são eliminadas, dada a premissa de geração hídrica acima da energia firme. Desta forma, quando o prêmio não é considerado, a mudança de modelo protege o comprador da exposição negativa ao PLD no cenário folga, mas o faz perder a energia recebida a PLD pelo gerador hidrelétrico no cenário restritivo. Assim, a perda esperada para o comprador deve ser compensada por um prêmio pago pelo gerador hidrelétrico no modelo proposto, de forma que o custo esperado do comprador nos dois modelos se torne equivalente.

Para a mensuração deste prêmio, foram utilizados os dados apresentados e duas simulações de PLDs para o submercado do SE/CO, feitas pelo programa Newave. O Newave é um modelo de otimização para o planejamento das metas de geração das usinas de um sistema hidrotérmico, de forma a minimizar o valor esperado do custo da operação para o período em análise (Cepel, 2013). Foram feitas duas simulações, uma com base em dados de junho de 2015 (deck de junho) e a outra com base em dezembro de 2015 (deck de dezembro), ambas com séries de 2.000 PLDs mensais, simulando o ano de 2016. 
5

\section{Resultados}

\section{1.}

\section{Resultados com 10 PLDs}

Os resultados estão divididos em duas partes para facilitar a compreensão e a intuição do modelo. Na primeira parte, são utilizadas as médias dos intervalos entre os decis da simulação de PLDs, resultando em dez valores representativos de PLDs. Na segunda parte, a liquidação da CCEE foi calculada para todos os valores das simulações dos dois decks e as análises finais são feitas sobre as simulações completas de PLDs.

A Tabela 2 mostra as médias dos intervalos decis de cada uma das duas simulações feitas pelo programa Newave. É possível observar que a simulação feita a partir de dados de junho, quando a crise hidrológica estava mais intensa, apresenta média total de $144 \mathrm{R} \$ / \mathrm{MWh}$, enquanto a média da simulação de dezembro é de 85 R\$/MWh, projetando um cenário mais favorável para 2016.

\begin{tabular}{lcc}
\multicolumn{3}{c}{ Tabela 2 - Média dos Intervalos Entre Decis da Simulação de } \\
\hline \multicolumn{3}{c}{ Simulações PLDs } \\
\hline R\$/MWh & Deck Junho & Deck Dezembro \\
\hline Média Decil 10 & 388 & 272 \\
Média Decil 9 & 317 & 142 \\
Média Decil 8 & 216 & 109 \\
Média Decil 7 & 161 & 87 \\
Média Decil 6 & 121 & 68 \\
Média Decil 5 & 87 & 46 \\
Média Decil 4 & 58 & 32 \\
Média Decil 3 & 34 & 32 \\
Média Decil 2 & 30 & 32 \\
Média Decil 1 & 30 & 32 \\
\hline Média & $\mathbf{1 4 4}$ & $\mathbf{8 5}$ \\
\hline
\end{tabular}

No deck de junho, verifica-se que as primeiras seis médias dos intervalos entre decis são inferiores ao CVU (de $155 \mathrm{R} \$ / \mathrm{MWh}$ ), enquanto as demais médias 
dos intervalos entre decis superam este custo. Desta forma, os primeiros seis valores representam o cenário folga ilustrado anteriormente, nos quais a UHE gera 55,7 GWmed e a UTE não é acionada. Em contrapartida, com os quatro PLDs restantes, a UTE será acionada, gerando 15 GWmed e reduzindo a geração hídrica a 40,7 GWmed, como mostra a Tabela 3. No deck de dezembro, entretanto, apenas a média do intervalo decil 10 se encaixa no cenário restritivo, enquanto os outros valores representam cenários folga, com a UHE gerando 55,7 GWmed.

Tabela 3 - Operação relativa a cada Decil

\begin{tabular}{lccccc}
\hline & & \multicolumn{4}{c}{ Operação (GWmed) } \\
\cline { 3 - 6 } Deck & Médias Decis & & & & \\
Junho & (R\$MWh) & Geração UHE & Geração UTE & Geração Base & Carga Total \\
\hline Decil 10 & 388 & 40,7 & 15 & 10,8 & 66,5 \\
Decil 9 & 317 & 40,7 & 15 & 10,8 & 66,5 \\
Decil 8 & 216 & 40,7 & 15 & 10,8 & 66,5 \\
Decil 7 & 161 & 40,7 & 15 & 10,8 & 66,5 \\
Decil 6 & 121 & 55,7 & 0 & 10,8 & 66,5 \\
Decil 5 & 87 & 55,7 & 0 & 10,8 & 66,5 \\
Decil 4 & 58 & 55,7 & 0 & 10,8 & 66,5 \\
Decil 3 & 34 & 55,7 & 0 & 10,8 & 66,5 \\
Decil 2 & 30 & 55,7 & 0 & 10,8 & 66,5 \\
Decil 1 & 30 & 55,7 & 0 & 10,8 & 66,5 \\
\hline & & & & & \\
Deck & Médias Decis & & & & \\
Dezembro & (R\$MWh) & Geração UHE & Geração UTE & Geração Base & Carga Total \\
\hline Decil 10 & 272 & 40,7 & 15 & 10,8 & 66,5 \\
Decil 9 & 142 & 55,4 & 0 & 10,8 & 66,5 \\
Decil 8 & 109 & 55,7 & 0 & 10,8 & 66,5 \\
Decil 7 & 87 & 55,7 & 0 & 10,8 & 66,5 \\
Decil 6 & 68 & 55,7 & 0 & 10,8 & 66,5 \\
Decil 5 & 46 & 55,7 & 0 & 10,8 & 66,5 \\
Decil 4 & 32 & 55,7 & 0 & 10,8 & 66,5 \\
Decil 3 & 32 & 55,7 & 0 & 10,8 & 66,5 \\
Decil 2 & 32 & 55,7 & 0 & 10,8 & 66,5 \\
Decil 1 & 32 & 55,7 & & & 66,5 \\
\hline & & & & & \\
\hline
\end{tabular}

$\mathrm{Na}$ ótica contratual do modelo atual, mesmo quando a geração hídrica é 40,7 GWmed no cenário folga, o contrato permanece em 53,2 GWmed. Porém, neste cenário de PLD superior ao CVU, a UTE é acionada, gerando 15 GWmed relativos à parcela flexível do contrato por disponibilidade feito com a usina térmica. Considerando os 10,8 GWmed de energia da base, a liquidação da CCEE é a diferença entre o total dos contratos - considerando a energia contratada por quantidade fixa e a energia contratada por disponibidade apenas quando gerada e a carga demandada, de 66,5 GWmed. 
A Tabela 4 mostra a visão contratual do modelo atual e a do modelo proposto, no qual a energia hídrica é dividida entre os contratos por quantidade e disponibilidade, para os decks de junho e dezembro. No modelo proposto, enquanto o contrato por quantidade permanece $40 \mathrm{GWmed}$ independente do cenário, o contrato por disponibilidade apresenta apenas a quantidade de fato gerada acima de $40 \mathrm{GWmed}$. Desta forma, nos cenários restritivos, nos quais a UHE gera 40,7 GWmed pelos dados do modelo conceitual, o contrato por disponibilidade apresenta 0,7 GWmed. Em cenários de folga, nos quais a geração hídrica é 55,7 GWmed pelo modelo, o contrato por disponibilidade contemplará 15,7 GWmed. Portanto, no modelo proposto, a liquidação da CCEE sempre será zero.

Tabela 4 - Balanços contratuais nos modelos atual e proposto

\begin{tabular}{|c|c|c|c|c|c|c|c|c|}
\hline \multicolumn{9}{|c|}{ Deck Junho } \\
\hline \multicolumn{4}{|c|}{$\begin{array}{c}\text { Balanço Contrato CCEE - Modelo Atual } \\
\text { (GWmed) }\end{array}$} & \multicolumn{5}{|c|}{$\begin{array}{c}\text { Balanço Contrato CCEE - Modelo Proposto } \\
\text { (GWmed) }\end{array}$} \\
\hline UHE & UTE & $\begin{array}{c}\text { Energia } \\
\text { Base }\end{array}$ & Liquidação & UHE & UHE & UTE & $\begin{array}{c}\text { Energia } \\
\text { Base }\end{array}$ & Liquidação \\
\hline Quant. & Disponib. & Contratada & CCEE & Quant. & Disponib. & Disponib. & Contratada & CCEE \\
\hline 53,2 & 15 & 10,8 & 12,5 & 40 & 0,7 & 15 & 10,8 & 0 \\
\hline 53,2 & 15 & 10,8 & 12,5 & 40 & 0,7 & 15 & 10,8 & 0 \\
\hline 53,2 & 15 & 10,8 & 12,5 & 40 & 0,7 & 15 & 10,8 & 0 \\
\hline 53,2 & 15 & 10,8 & 12,5 & 40 & 0,7 & 15 & 10,8 & 0 \\
\hline 53,2 & 0 & 10,8 & $-2,5$ & 40 & 15,7 & 0 & 10,8 & 0 \\
\hline 53,2 & 0 & 10,8 & $-2,5$ & 40 & 15,7 & 0 & 10,8 & 0 \\
\hline 53,2 & 0 & 10,8 & $-2,5$ & 40 & 15,7 & 0 & 10,8 & 0 \\
\hline 53,2 & 0 & 10,8 & $-2,5$ & 40 & 15,7 & 0 & 10,8 & 0 \\
\hline 53,2 & 0 & 10,8 & $-2,5$ & 40 & 15,7 & 0 & 10,8 & 0 \\
\hline 53,2 & 0 & 10,8 & $-2,5$ & 40 & 15,7 & 0 & 10,8 & 0 \\
\hline \multicolumn{9}{|c|}{ Deck Dezembro } \\
\hline \multicolumn{4}{|c|}{$\begin{array}{c}\text { Balanço Contrato CCEE - Modelo Atual } \\
\text { (GWmed) }\end{array}$} & \multicolumn{5}{|c|}{$\begin{array}{c}\text { Balanço Contrato CCEE - Modelo Proposto } \\
\text { (GWmed) }\end{array}$} \\
\hline UHE & UTE & $\begin{array}{c}\text { Energia } \\
\text { Base }\end{array}$ & Liquidação & UHE & UHE & UTE & $\begin{array}{c}\text { Energia } \\
\text { Base }\end{array}$ & Liquidação \\
\hline Quant. & Disponib. & Contratada & CCEE & Quant. & Disponib. & Disponib. & Contratada & CCEE \\
\hline 53,2 & 15 & 10,8 & 12,5 & 40 & 0,7 & 15 & 10,8 & 0 \\
\hline 53,2 & 0 & 10,8 & $-2,5$ & 40 & 15,7 & 0 & 10,8 & 0 \\
\hline 53,2 & 0 & 10,8 & $-2,5$ & 40 & 15,7 & 0 & 10,8 & 0 \\
\hline 53,2 & 0 & 10,8 & $-2,5$ & 40 & 15,7 & 0 & 10,8 & 0 \\
\hline 53,2 & 0 & 10,8 & $-2,5$ & 40 & 15,7 & 0 & 10,8 & 0 \\
\hline 53,2 & 0 & 10,8 & $-2,5$ & 40 & 15,7 & 0 & 10,8 & 0 \\
\hline 53,2 & 0 & 10,8 & $-2,5$ & 40 & 15,7 & 0 & 10,8 & 0 \\
\hline 53,2 & 0 & 10,8 & $-2,5$ & 40 & 15,7 & 0 & 10,8 & 0 \\
\hline 53,2 & 0 & 10,8 & $-2,5$ & 40 & 15,7 & 0 & 10,8 & 0 \\
\hline 53,2 & 0 & 10,8 & $-2,5$ & 40 & 15,7 & 0 & 10,8 & 0 \\
\hline
\end{tabular}


Para achar o valor do prêmio para cada deck, é preciso mensurar a liquidação na CCEE do modelo atual que, se for positiva, corresponde à perda do comprador com a troca de modelos e, se negativa, representa o ganho do comprador com a mudança. Como a quantidade da liquidação da CCEE é recebida ou comprada a PLD, basta multiplicá-la pelo PLD e converter de GWmed em MWh, multiplicando por 1000 e depois por 730, considerando 730 horas médias em 1 mês.

A Tabela 5 mostra a liquidação da CCEE para o comprador em quantidade e em reais. É possível observar que ambas as médias da liquidação na CCEE são positivas, indicando que a exposição do comprador ao PLD é vantajosa a este, pois ainda que em cenários de folga sua exposição se torne negativa, a exposição positiva do cenário restritivo supera os prejuízos do primeiro cenário. Uma explicação é o fato do PLD estar mais alto nos cenários nos quais o comprador pode vender a energia excedente, enquanto o PLD se encontra em patamares mais baixos nos cenários folga.

Tabela 5 - Liquidação CCEE em milhões $\mathrm{R} \$$ com carga de 66,5 GWmed

\begin{tabular}{|c|c|c|c|c|c|c|c|}
\hline \multicolumn{4}{|c|}{ Deck de Junho } & \multicolumn{4}{|c|}{ Deck de Dezembro } \\
\hline \multicolumn{2}{|c|}{$\begin{array}{l}\text { Média dos decis } \\
\text { das } \\
\text { simulações de } \\
\text { PLDs } \\
\end{array}$} & \multirow{2}{*}{$\begin{array}{c}\begin{array}{c}\text { Liquidação } \\
\text { CCEE } \\
\text { (GWmed) }\end{array} \\
12,5\end{array}$} & \multirow{2}{*}{$\begin{array}{c}\begin{array}{c}\text { Liquidação } \\
\text { CCEE } \\
\text { (R\$ milhões) }\end{array} \\
3545\end{array}$} & \multicolumn{2}{|c|}{$\begin{array}{l}\text { Média dos decis } \\
\text { das } \\
\text { simulações de } \\
\text { PLDs }\end{array}$} & \multirow{2}{*}{$\begin{array}{c}\begin{array}{c}\text { Liquidação } \\
\text { CCEE } \\
\text { (GWmed) }\end{array} \\
12,5\end{array}$} & \multirow{2}{*}{$\begin{array}{c}\begin{array}{c}\text { Liquidação } \\
\text { CCEE }\end{array} \\
\text { (R\$ milhões) } \\
2478\end{array}$} \\
\hline Decil 10 & 388 & & & Decil 10 & 272 & & \\
\hline Decil 9 & 317 & 12,5 & 2890 & Decil 9 & 142 & $-2,5$ & -260 \\
\hline Decil 8 & 216 & 12,5 & 1971 & Decil 8 & 109 & $-2,5$ & -198 \\
\hline Decil 7 & 161 & 12,5 & 1466 & Decil 7 & 87 & $-2,5$ & -158 \\
\hline Decil 6 & 121 & $-2,5$ & -221 & Decil 6 & 68 & $-2,5$ & -123 \\
\hline Decil 5 & 87 & $-2,5$ & -159 & Decil 5 & 46 & $-2,5$ & -84 \\
\hline Decil 4 & 58 & $-2,5$ & -106 & Decil 4 & 32 & $-2,5$ & -59 \\
\hline Decil 3 & 34 & $-2,5$ & -63 & Decil 3 & 32 & $-2,5$ & -58 \\
\hline Decil 2 & 30 & $-2,5$ & -55 & Decil 2 & 32 & $-2,5$ & -58 \\
\hline Decil 1 & 30 & $-2,5$ & -55 & Decil 1 & 32 & $-2,5$ & -58 \\
\hline Média & 144 & 3,5 & 921 & Média & 85 & $-1,0$ & 142 \\
\hline
\end{tabular}

A Tabela 6 mostra a liquidação da CCEE caso a carga fosse de 72,3 GWmed, número possivelmente mais próximo ao real em um cenário econômico estável, por ter sido projetado em 2013. É possível notar que, pelo deck de dezembro, a liquidação da CCEE em um cenário de estabilidade ficaria em torno de $\mathrm{R} \$ 218$ negativos, revelando que o beneficiado pela troca de modelos nesta simulação seria o comprador. Neste cenário, para manter seu custo esperado 
equivalente nos dois modelos, o comprador deve pagar um prêmio ao gerador, e não o contrário.

Tabela 6 - Liquidação CCEE em milhões $\mathbf{R} \$$ com carga de 72,3 GWmed

\begin{tabular}{|c|c|c|c|c|c|c|c|}
\hline \multicolumn{4}{|c|}{ Deck de Junho } & \multicolumn{4}{|c|}{ Deck de Dezembro } \\
\hline \multicolumn{2}{|c|}{$\begin{array}{l}\text { Média dos decis } \\
\text { das } \\
\text { simulações de } \\
\text { PLDs }\end{array}$} & \multirow{2}{*}{$\begin{array}{c}\begin{array}{c}\text { Liquidação } \\
\text { CCEE } \\
\text { (GWmed) }\end{array} \\
6,7\end{array}$} & \multirow{2}{*}{$\begin{array}{c}\begin{array}{c}\text { Liquidação } \\
\text { CCEE }\end{array} \\
\text { (R\$ milhões) } \\
1900\end{array}$} & \multicolumn{2}{|c|}{$\begin{array}{l}\text { Média dos decis } \\
\text { das } \\
\text { simulações de } \\
\text { PLDs }\end{array}$} & \multirow{2}{*}{$\begin{array}{c}\begin{array}{c}\text { Liquidação } \\
\text { CCEE } \\
\text { (GWmed) }\end{array} \\
6,7\end{array}$} & \multirow{2}{*}{$\begin{array}{c}\begin{array}{c}\text { Liquidação } \\
\text { CCEE }\end{array} \\
\text { (R\$ milhões) } \\
1328\end{array}$} \\
\hline Decil 10 & 388 & & & Decil 10 & 272 & & \\
\hline Decil 9 & 317 & 6,7 & 1549 & Decil 9 & 142 & $-8,3$ & -863 \\
\hline Decil 8 & 216 & 6,7 & 1056 & Decil 8 & 109 & $-8,3$ & -659 \\
\hline Decil 7 & 161 & 6,7 & 786 & Decil 7 & 87 & $-8,3$ & -525 \\
\hline Decil 6 & 121 & $-8,3$ & -733 & Decil 6 & 68 & $-8,3$ & -409 \\
\hline Decil 5 & 87 & $-8,3$ & -529 & Decil 5 & 46 & $-8,3$ & -279 \\
\hline Decil 4 & 58 & $-8,3$ & -351 & Decil 4 & 32 & $-8,3$ & -197 \\
\hline Decil 3 & 34 & $-8,3$ & -208 & Decil 3 & 32 & $-8,3$ & -193 \\
\hline Decil 2 & 30 & $-8,3$ & -183 & Decil 2 & 32 & $-8,3$ & -193 \\
\hline Decil 1 & 30 & $-8,3$ & -183 & Decil 1 & 32 & $-8,3$ & -193 \\
\hline Média & 144 & $-2,3$ & 310 & Média & 85 & $-6,8$ & -218 \\
\hline
\end{tabular}

Por fim, para achar o prêmio esperado de cada deck, que será a diferença entre os preços dos contratos de quantidade e disponibilidade, é necessário dividir a liquidação média da CCEE pelo montante de energia contratado por disponibilidade no novo modelo. Pelos dados do modelo conceitual, este montante é de 13,2 GWmed, que é a diferença entre a garantia física da usina (53,2 GWmed) e sua energia firme (40 GWmed). Como o montante do contrato por disponibilidade está em GWmed e o prêmio será em $\mathrm{R} \$ / \mathrm{MWh}$, é preciso fazer a transformação para MWh e, depois, dividir a liquidação média por este resultado.

A Tabela 7 mostra os prêmios esperados de cada deck, tanto para a carga de 66,5 GWmed como para a carga de 73,2 GWmed. O preço do contrato por disponibilidade das hidrelétricas corresponde ao preço por quantidade, 130 $\mathrm{R} \$ / \mathrm{MW}$, menos o prêmio esperado, isto é, o "desconto" que deve ser dado pelo gerador para manter o custo esperado do comprador constante.

Tabela 7 - Prêmio esperado considerando 10 PLDs

\begin{tabular}{lcc|cccc}
\hline & \multicolumn{3}{c}{ Deck Junho } & \multicolumn{2}{c}{ Deck Dezembro } & \\
\cline { 2 - 5 } & $\mathbf{6 6 , 5}$ & $\mathbf{7 2 , 3}$ & $\mathbf{6 6 , 5}$ & $\mathbf{7 2 , 3}$ & GWmed \\
\hline Liquidação Média CCEE & 921 & 310 & 142 & -218 & $\mathrm{R} \$$ milhões \\
Prêmio Esperado & 96 & 32 & 15 & -23 & $\mathrm{R} \$ \mathrm{MWh}$ \\
Preço do Contrato por Disponibilidade & 34 & 98 & 115 & 153 & $\mathrm{R} \$ / \mathrm{MWh}$ \\
\hline
\end{tabular}


Como já observado nos resultados da liquidação da CCEE, a simulação de dezembro para a carga de 72,3 GWmed projeta um cenário mais desfavorável para o comprador em 2016 no modelo atual do que no modelo proposto, isto é, a troca de modelos seria vantajosa para o comprador em termos de custos. Portanto, para permanecer com os mesmos custos nos dois modelos, o comprador deveria pagar um prêmio de $23 \mathrm{R} \$ / \mathrm{MWh}$ no contrato por disponibilidade, cujo preço resultaria em $153 \mathrm{R} \$ / \mathrm{MWh}$.

Nos outros cenários, entretanto, o comprador é prejudicado em termos de custos totais com a troca de modelos, fazendo com que o prêmio tenha que ser pago pelo gerador para igualar os custos esperados do comprador. Ainda assim, é perceptível a sensibilidade do valor do prêmio, que reduziu mais de $84 \%$ entre os decks de junho e dezembro para a carga de 66,5GWmed.

\section{2.}

\section{Resultados com 2.000 PLDs Mensais}

Enquanto a seção anterior apresentou resultados com as médias entre decis das séries de PLDs simulados, nesta seção e nas seguintes serão apresentados os resultados e análises utilizando as séries mensais de 2.000 PLDs cada, mantendo as mesmas premissas. Para cada PLD simulado, foi calculada uma receita para o gerador, utilizando a decisão do operador do sistema de gerar 15GWmed de energia térmica caso o PLD seja maior do que o CVU e zero caso contrário. Assim, seguindo a mesma formulação utilizada para o modelo com 10 PLDs, foram calculadas séries mensais de 2.000 receitas para o gerador, considerando a exposição deste ao mercado de curto prazo.

A Tabela 8 mostra os resultados de liquidação média da CCEE, o prêmio esperado e preço do contrato por disponibilidade quando são utilizados todos os valores das 2.000 séries mensais de PLDs para 2016.

Tabela 8 - Prêmio esperado considerando 2.000 séries mensais de PLD

\begin{tabular}{|c|c|c|c|c|c|}
\hline & \multicolumn{2}{|c|}{ Deck Junho } & \multicolumn{2}{|c|}{ Deck Dezembro } & \multirow[b]{2}{*}{ GWmed } \\
\hline & 66,5 & 72,3 & 66,5 & 72,3 & \\
\hline Liquidação Média CCEE & 863 & 252 & 175 & -185 & $\mathrm{R} \$$ milhões \\
\hline Prêmio Esperado & 90 & 26 & 18 & -19 & $\mathrm{R} \$ / \mathrm{MWh}$ \\
\hline Preço do Contrato por Disponibilidade & 40 & 104 & 112 & 149 & $\mathrm{R} \$ / \mathrm{MWh}$ \\
\hline
\end{tabular}


Podemos observar uma relativa proximidade dos números encontrados com os resultados com 10 valores de PLDs. A sensibilidade do prêmio em relação à carga demandada e aos decks continua significativa, variando de $-185 \mathrm{R} \$ / \mathrm{MWh}$ a $863 \mathrm{R} \$ / \mathrm{MWh}$. Se calcularmos os prêmios mensalmente, é perceptível a instabilidade do prêmio ao longo do tempo, principalmente no deck de Junho com a carga de 72,3 GWmed, no qual o prêmio chegou a cair mais de $88 \%$ de janeiro a dezembro (Tabela 9). Em termos absolutos, a maior variação foi deste mesmo deck para a carga de 66,5 GWmed, que variou 114,4 R\$/MWh em doze meses.

Tabela 9 - Prêmio Esperado para cada mês de 2016

\begin{tabular}{lll|lll}
\hline & \multicolumn{2}{c}{ Deck Junho } & \multicolumn{2}{c}{ Deck Dezembro } & \\
\cline { 2 - 5 } & $\mathbf{6 6 , 5}$ & $\mathbf{7 2 , 3}$ & $\mathbf{6 6 , 5}$ & $\mathbf{7 2 , 3}$ & GWmed \\
\hline Jan & 169,6 & 74,1 & 12,9 & $-30,3$ & \\
Fev & 126,7 & 47,4 & 22,5 & $-19,3$ & \\
Mar & 106,7 & 34,6 & 25,1 & $-15,3$ & \\
Abr & 95,7 & 29,0 & 20,7 & $-18,4$ & \\
Mai & 85,7 & 23,2 & 21,8 & $-16,3$ & \\
Jun & 82,9 & 22,1 & 18,1 & $-19,8$ & R $\$ / \mathrm{MWh}$ \\
Jul & 79,4 & 20,1 & 16,4 & $-20,7$ & \\
Ago & 74,2 & 16,9 & 13,5 & $-22,6$ & \\
Set & 70,8 & 14,9 & 16,3 & $-18,9$ & \\
Out & 66,4 & 12,6 & 17,6 & $-17,0$ & \\
Nov & 61,5 & 10,7 & 17,4 & $-16,4$ & \\
Dez & 55,2 & 8,3 & 15,4 & $-16,1$ & \\
\hline
\end{tabular}

Os resultados dos prêmios indicam, portanto, uma desvantagem no modelo apresentado. Ao longo do tempo, o prêmio definido no contrato por quantidade pode variar de forma que o objetivo de manter a equivalência dos custos do comprador nos dois modelos não seja mais atingido.

\subsection{1.}

\section{Análise de Sensibilidade}

Pelos resultados apresentados já é possível observar uma variação no valor do prêmio entre os decks e entre as duas projeções de carga. Para uma melhor visualização da sensibilidade do prêmio em relação à configuração do sistema, foram utilizados diferentes valores para três fatores do modelo conceitual - carga do sistema, energia da base e CVU da usina térmica - e realizadas análises de 
sensibilidade, observando como o valor do prêmio se comporta sob os diferentes cenários.

A Figura 6, referente à sensibilidade do prêmio em relação à carga do sistema, mostra que quanto maior a carga, menor é o prêmio pago pelo gerador hidrelétrico, ou maior é o prêmio pago pelo comprador. Dessa forma, na inexistência de pagamento de prêmio, um aumento de carga no modelo atual aumentaria a preferência do comprador pela mudança ao modelo proposto, pois esta mudança reduziria seus custos esperados. Isto ocorre porque, nos cenários restritivos, como a capacidade instalada da térmica de $15 \mathrm{GWmed}$ já está sendo utilizada, o operador do sistema deve aumentar a geração hídrica para suprir a demanda. Assim, o gerador precisa comprar menos energia no mercado de curto prazo do que em um cenário de menor carga, no qual a diferença entre a garantia física e a geração é maior. Utilizando cargas de 63 GWmed a 75 Gwmed, o prêmio variou de $128 \mathrm{R} \$ / \mathrm{MWh}$ a $-3 \mathrm{R} \$ / \mathrm{MWh}$ no deck de junho e de $41 \mathrm{R} \$ / \mathrm{MWh}$ a -37 R\$/MWh no deck de dezembro.

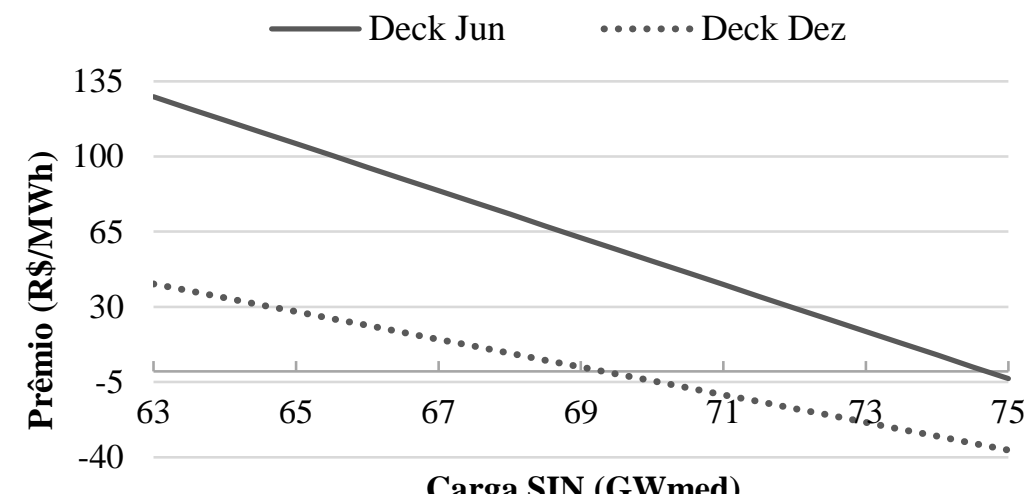

Carga SIN (GWmed)

Figura 6 - Análise de sensibilidade do prêmio em relação à carga do sistema

$\mathrm{Na}$ análise de sensibilidade do prêmio em relação a variações na energia da base, que no modelo inicial é fixada em 10,8 GWmed, verifica-se que, mantendo os demais fatores constantes, quanto maior a energia de base, maior o prêmio a ser pago pelo gerador hidrelétrico, ou menor o prêmio a ser pago pelo comprador. A Figura 7 mostra a sensibilidade do prêmio com valores de energia de base de 4GWmed a 16GWmed. No deck de dezembro, o prêmio variou de $-26 \mathrm{R} \$ \mathrm{MWh}$ a $52 \mathrm{R} \$ / \mathrm{MWh}$, enquanto no de junho o prêmio máximo foi de $146 \mathrm{R} \$ / \mathrm{MWh}$. A relação positiva entre a energia de base e o prêmio ocorre porque, dado que a capacidade instalada da UTE é integralmente utilizada nos cenários críticos, 
quanto maior a energia de base, menos energia hídrica é necessária para suprir a demanda e, assim, maior a diferença entre a garantia física e a geração real da UHE. Como esta diferença caracteriza o cenário restritivo, no qual o comprador é positivamente exposto ao PLD no modelo atual, é necessário um prêmio maior para que os custos totais esperados do comprador não se alterem com a troca de modelos.

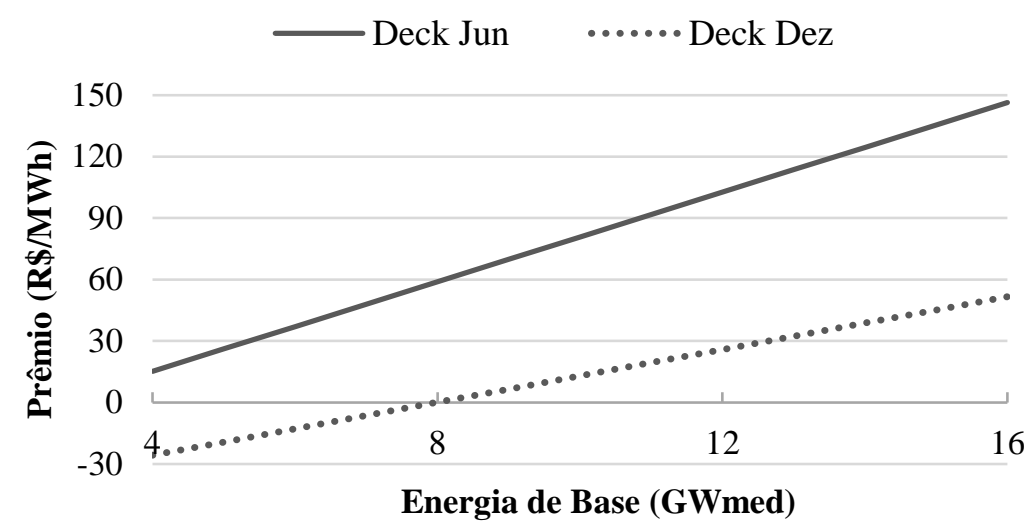

Figura 7 - Análise de sensibilidade do prêmio em relação à energia da base

Por fim, a Figura 8 mostra a sensibilidade do valor do prêmio em relação ao CVU da usina térmica. Com um CVU mais alto, alguns valores de PLD, que antes estavam acima do CVU e caracterizavam um cenário restritivo, passam a ser comparativamente mais baratos, caracterizando um cenário folga. Como o comprador é exposto ao PLD no cenário folga do modelo atual, esta mudança de cenários faz com que o comprador aumente sua preferência pelo modelo proposto. Dessa forma, quando a variação de CVU ultrapassa valores de PLD, o prêmio pago pelo gerador é reduzido.

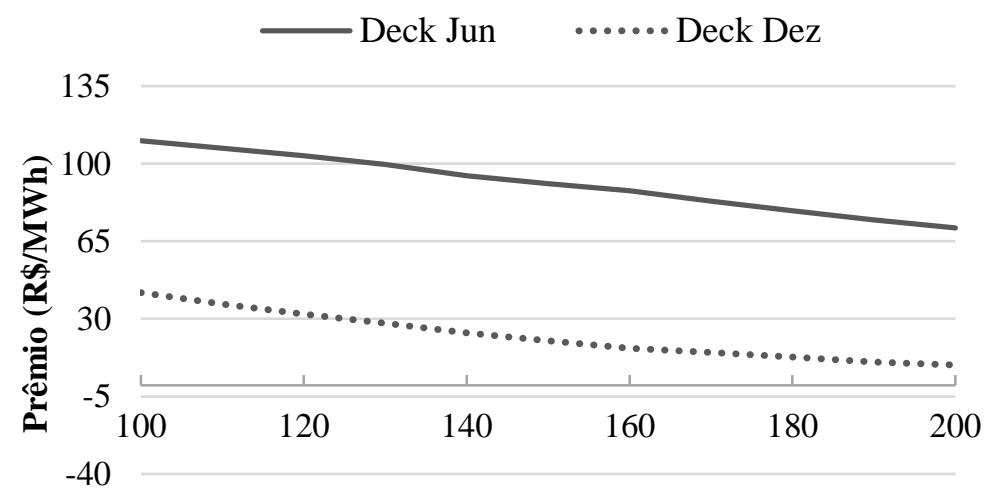

CVU UTE (R\$MWh)

Figura 8 - Análise de sensibilidade do prêmio em relação ao CVU da UTE 
A partir destas análises e das diferenças entre os decks de junho e dezembro, é perceptível a alta sensibilidade do prêmio em relação a fatores do modelo e aos momentos nos quais as simulações foram realizadas.

\subsection{2.}

\section{Equivalente de Certeza}

Com base nas séries mensais de receitas para o gerador no modelo atual, calculadas a partir das simulações de PLDs e da formulação apresentada, foram calculados valores de utilidade para o gerador em cada mês, para cada deck e cenário de carga. Assumindo aversão ao risco por parte do gerador, foi aplicada a função utilidade (20) sobre as receitas esperadas do modelo atual, onde o parâmetro $a$ é o coeficiente de aversão ao risco e $b$ é a receita simulada considerando a exposição ao PLD.

$$
U=\frac{1-e^{-a b}}{a}
$$

A função (20) é apropriada para problemas de preferências de valores monetários por ser uma função monotonicamente crescente, isto é, quanto maior a receita $(b)$, maior a utilidade $(U)$ do gerador (Keeney \& Raiffa, 1993). Esta propriedade pode ser verificada por meio da primeira derivada da função, que é positiva para todo $b(21)$.

$$
U^{\prime}=e^{-a b}
$$

Além disso, a segunda derivada (22) é negativa para coeficientes de aversão ao risco positivas, isto é, a função utilidade se torna côncava. Desta forma, para agentes avessos a risco $(a>0)$, a queda na receita reflete uma maior perda em termos de utilidade do que um ganho monetário refletiria em ganhos de utilidade (Elton et al, 2014).

$$
U^{\prime \prime}=-a \cdot e^{-a b}
$$

Em relação à aversão ao risco, quanto menor o coeficiente de aversão ao risco, maior o valor de utilidade o gerador pode atingir. A Figura 9 mostra o comportamento da função (20) com três diferentes valores para $a$. 


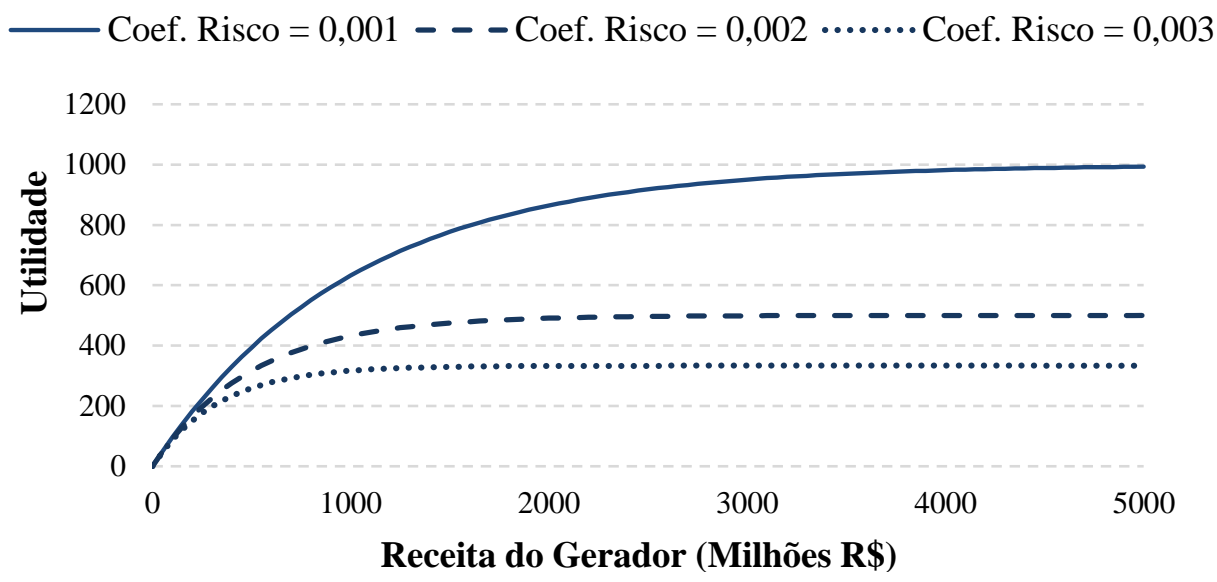

Figura 9 - Função Utilidade com diferentes coeficientes de aversão ao risco

Assumindo também tolerância ao risco constante, é possível calcular o equivalente de certeza $(\hat{b})$ para cada mês de 2016, a partir da equação (23), na qual $U$ é a utilidade esperada do gerador para determinado mês.

$$
\hat{b}=\frac{-\log (1-a U)}{a}
$$

Desta forma, o equivalente de certeza de cada mês foi calculado a partir das médias das utilidades das receitas calculadas a partir da simulação de PLDs. A Figura 10 mostra a diferença entre o equivalente de certeza do modelo proposto e o modelo atual, para cada deck e cenário de carga. Para fins ilustrativos, o coeficiente de aversão ao risco utilizado foi de 0,001 . Como a receita é fixa no modelo proposto, a certeza equivalente deste modelo corresponde à receita fixa calculada.

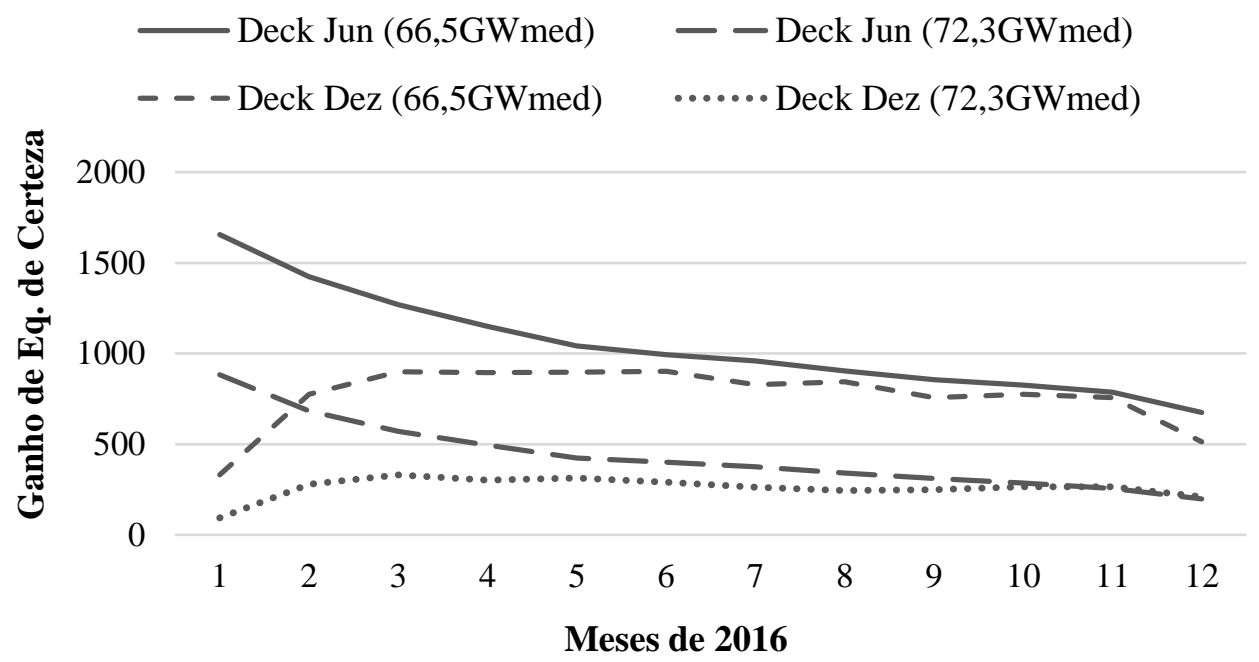

Figura 10 - Ganhos de Equivalente de Certeza dos Geradores Hidrelétricos 
Os resultados mostraram diferenças positivas entre o modelo proposto e o atual, isto é, ganhos de equivalente de certeza devido à aplicação do modelo proposto para o gerador em todos os cenários analisados. O maior ganho foi observado no deck de junho com cenário de carga de 66,5 GWmed, cujos resultados de receita foram os piores para os geradores em relação aos outros cenários. Como o modelo proposto elimina a exposição do gerador à variabilidade do PLD e o prêmio é calculado de forma a manter o custo esperado total do comprador equivalente nos dois modelos, qualquer nível de aversão ao risco do gerador torna o modelo proposto mais vantajoso a este.

\subsection{3.}

\section{Conditional Value-at-Risk (CVaR) para o Gerador}

Como mencionado na seção de referencial teórico, o CVaR é a medida de risco mais indicada, quando comparada ao $\mathrm{VaR}$, para avaliar perdas em mercados de energia. O cálculo do $\mathrm{CVaR}$ para o gerador foi feito a partir da parte variável da receita das hidrelétricas, isto é, a exposição ao PLD. Portanto, os valores utilizados correspondem aos resultados dos geradores na liquidação da CCEE.

Uma das formas atualmente acessíveis pelos geradores para a redução dos riscos é considerar uma margem de segurança na quantidade de energia vendida contratualmente. Assim, os geradores podem negociar um nível de contratação abaixo da garantia física da usina, se comprometendo a entregar uma quantidade menor de energia do que $100 \%$ da garantia física. Desta forma, para a análise de $\mathrm{CVaR}$, também foram considerados cenários nos quais os geradores contratam $95 \%$ ou $90 \%$ da garantia física da usina.

A Tabela 10 mostra os resultados do cálculo do CVaR médio mensal para três níveis de confiança $(90 \%, 95 \%$ e $99 \%)$, evidenciando as possíveis perdas às quais o gerador é exposto no modelo atual. $\mathrm{O}$ cálculo do CVaR não se aplica ao modelo proposto dado que a receita mensal é fixa neste caso e, portanto, não há liquidação da CCEE. Os valores também mostram que mesmo para contratos com uma margem de segurança de $10 \%$, o modelo proposto ainda é eficaz na redução de riscos. Desta forma, é possível perceber que o modelo proposto é mais vantajoso nos dois cenários de carga para as duas simulações nos cenários mais 
críticos de geração, resultado alinhado com a proposta do novo modelo de reduzir a exposição dos geradores aos riscos hidrológicos.

Tabela 10 - Análise de CVaR para o gerador no Modelo Atual

\begin{tabular}{|c|c|c|c|c|c|c|}
\hline & & \multicolumn{2}{|c|}{ Deck Junho } & \multicolumn{2}{|c|}{ Deck Dezembro } & \multirow[b]{2}{*}{ (GWmed) } \\
\hline & & 66,5 & 72,3 & 66,5 & 72,3 & \\
\hline \multirow{3}{*}{$\begin{array}{c}100 \% \\
\text { Contratado }\end{array}$} & CVaR 90\% & $-3499,21$ & $-1875,58$ & $-2454,58$ & $-1314,04$ & \multirow{9}{*}{$\begin{array}{c}\text { (R\$ } \\
\text { milhões) }\end{array}$} \\
\hline & CVaR 95\% & $-3544,88$ & $-1900,06$ & $-3110,09$ & $-1667,01$ & \\
\hline & CVaR 99\% & $-3544,88$ & $-1900,06$ & $-3710,62$ & $-1988,89$ & \\
\hline \multirow{3}{*}{$\begin{array}{c}95 \% \\
\text { Contratado }\end{array}$} & CVaR 90\% & $-2754,58$ & $-1130,94$ & $-1931,50$ & $-790,96$ & \\
\hline & CVaR 95\% & $-2790,53$ & $-1145,71$ & $-2448,26$ & $-1005,18$ & \\
\hline & CVaR 99\% & $-2790,53$ & $-1145,71$ & $-2921,00$ & $-1199,27$ & \\
\hline \multirow{3}{*}{$\begin{array}{c}90 \% \\
\text { Contratado }\end{array}$} & CVaR 90\% & $-2009,95$ & $-386,31$ & $-1408,43$ & $-267,89$ & \\
\hline & CVaR 95\% & $-2036,18$ & $-391,35$ & $-1786,43$ & $-343,35$ & \\
\hline & CVaR 99\% & $-2036,18$ & $-391,35$ & $-2131,38$ & $-409,65$ & \\
\hline
\end{tabular}

Para fins de comparação, a Tabela 11 mostra a diferença entre a receita mensal do modelo proposto e a receita do contrato por quantidade do modelo atual, no caso de $100 \%$ de contratação da garantia física. Com a simulação de junho e a carga de 66,5GWmed, os resultados mostraram uma perda de $\mathrm{R} \$ 863,07$ para o gerador. No entanto, no modelo proposto, embora haja esta queda na receita proveniente de contratos, este agente não estaria mais exposto às perdas exibidas na Tabela 10. Para o deck de dezembro, com carga de 72,3 GWmed, o modelo apresenta um ganho na receita do gerador com modelo proposto, o que ocorre pela alta probabilidade de haver geração de energia secundária neste cenário de carga e com o deck de PLDs mais baixos.

Tabela 11 - Diferença na receita proveniente de contratos

\begin{tabular}{lcc|ccc}
\hline & \multicolumn{4}{c}{ Deck Junho } & \multicolumn{2}{c}{ Deck Dezembro } & \\
\cline { 2 - 5 } & $\mathbf{6 6 , 5}$ & $\mathbf{7 2 , 3}$ & $\mathbf{6 6 , 5}$ & $\mathbf{7 2 , 3}$ & (GWmed) \\
\hline $\begin{array}{l}\text { Diferença Modelo Proposto } \\
\text { e Modelo Atual }\end{array}$ & $-863,07$ & $-252,11$ & $-174,76$ & 185,44 & (R \$ milhões) \\
\hline
\end{tabular}




\subsection{4. \\ Conditional Value-at-Risk (CVaR) para o Comprador}

Nos cenários de geração de energia hídrica acima da garantia física do modelo atual, os compradores ficam negativamente expostos ao PLD, pois precisam comprar a energia secundária no mercado de curto prazo para suprir a demanda. Esta exposição resulta em valores negativos na liquidação da CCEE, que corresponde à visão do comprador. No modelo proposto, entretanto, tanto o gerador quanto o comprador não ficam mais expostos ao PLD.

Como o contrato por disponibilidade daria ao comprador o direito a toda a energia gerada a partir do nível da energia firme, a liquidação da CCEE não teria mais como ser negativa. Valores positivos na CCEE também não são esperados no novo modelo, pois tal cenário só poderia ocorrer se a geração hídrica não alcançar o nível de energia firme. Assim, o valor esperado da liquidação na CCEE é zero.

Para a primeira análise de risco dos compradores no modelo atual, foram calculados os valores de CVaR mensais dos resultados na liquidação da CCEE para três níveis de confiança $(90 \%, 95 \%$ e $99 \%)$ e nos três cenários de contratação da garantia física $(90 \%, 95 \%$ e $100 \%)$, como mostra a Tabela 12. Quanto menor o nível de contratação, maior a exposição dos compradores, pois a geração que exceder este nível deve ser comprada ao PLD para suprir a demanda.

Tabela 12 - Análise de CVaR da Liquidação da CCEE no Modelo Atual

\begin{tabular}{|c|c|c|c|c|c|c|}
\hline & & \multicolumn{2}{|c|}{ Deck Junho } & \multicolumn{2}{|c|}{ Deck Dezembro } & \multirow[b]{2}{*}{ (GWmed) } \\
\hline & & 66,5 & 72,3 & 66,5 & 72,3 & \\
\hline \multirow{3}{*}{$\begin{array}{c}100 \% \\
\text { Contratado }\end{array}$} & CVaR 90\% & $-244,16$ & $-810,60$ & $-243,32$ & $-807,84$ & \multirow{9}{*}{$\begin{array}{c}\text { (R\$ } \\
\text { milhões) }\end{array}$} \\
\hline & CVaR 95\% & $-260,25$ & $-864,01$ & $-260,76$ & $-865,73$ & \\
\hline & CVaR 99\% & $-276,57$ & $-918,23$ & $-275,74$ & $-915,44$ & \\
\hline \multirow{3}{*}{$\begin{array}{c}95 \% \\
\text { Contratado }\end{array}$} & CVaR 90\% & $-503,94$ & $-1070,38$ & $-502,22$ & $-1066,73$ & \\
\hline & CVaR 95\% & $-537,15$ & $-1140,92$ & $-538,21$ & $-1143,18$ & \\
\hline & CVaR 99\% & $-570,85$ & $-1212,50$ & $-569,12$ & $-1208,83$ & \\
\hline \multirow{3}{*}{$\begin{array}{c}90 \% \\
\text { Contratado }\end{array}$} & CVaR 90\% & $-763,72$ & $-1330,16$ & $-761,12$ & $-1325,63$ & \\
\hline & CVaR 95\% & $-814,05$ & $-1417,82$ & $-815,66$ & $-1420,63$ & \\
\hline & CVaR 99\% & $-865,13$ & $-1506,78$ & $-862,50$ & $-1502,21$ & \\
\hline
\end{tabular}


Entretanto, quando consideramos o custo de acionar usinas térmicas em períodos de baixa geração hídrica, o $\mathrm{CVaR}$ deste agente piora com a troca de modelos. Isto ocorre porque, ao mesmo tempo que os possíveis prejuízos do gerador estão sendo distribuídos ao longo do tempo de forma a mitigar os riscos, os ganhos do comprador com a venda de energia em cenários restritivos também estão sendo distribuídos. A Tabela 13 mostra os valores de CVaR para os compradores quando são considerados, além da exposição ao PLD, os custos com CVU no modelo atual. Os resultados mostram que os valores de CVaR considerando o CVU, isto é, nos cenários de restrição, são próximos dos valores de CVaR considerando apenas a liquidação da CCEE, que é negativa nos cenários de folga.

Tabela 13 - Análise de CVaR com CVU para o comprador no Modelo Atual

\begin{tabular}{|c|c|c|c|c|c|c|}
\hline & & \multicolumn{2}{|c|}{ Deck Junho } & \multicolumn{2}{|c|}{ Deck Dezembro } & \multirow[b]{2}{*}{ (GWmed) } \\
\hline & & 66,5 & 72,3 & 66,5 & 72,3 & \\
\hline \multirow{3}{*}{$\begin{array}{c}100 \% \\
\text { Contratado }\end{array}$} & CVaR 90\% & $-248,47$ & $-873,25$ & $-246,85$ & $-854,65$ & \multirow{9}{*}{$\begin{array}{c}\text { (R\$ } \\
\text { milhões) }\end{array}$} \\
\hline & CVaR 95\% & $-263,02$ & $-901,72$ & $-262,72$ & $-893,56$ & \\
\hline & CVaR 99\% & $-276,87$ & $-926,86$ & $-276,33$ & $-924,59$ & \\
\hline \multirow{3}{*}{$\begin{array}{c}95 \% \\
\text { Contratado }\end{array}$} & CVaR 90\% & $-525,23$ & $-1187,35$ & $-518,74$ & $-1159,82$ & \\
\hline & CVaR 95\% & $-551,05$ & $-1210,28$ & $-547,57$ & $-1197,16$ & \\
\hline & CVaR 99\% & $-573,02$ & $-1230,95$ & $-572,49$ & $-1226,20$ & \\
\hline \multirow{3}{*}{$\begin{array}{c}90 \% \\
\text { Contratado }\end{array}$} & CVaR 90\% & $-818,47$ & $-1517,81$ & $-801,94$ & $-1492,65$ & \\
\hline & CVaR 95\% & $-847,25$ & $-1528,82$ & $-840,15$ & $-1519,13$ & \\
\hline & CVaR 99\% & $-872,46$ & $-1537,38$ & $-870,59$ & $-1534,03$ & \\
\hline
\end{tabular}

Na modelagem, a capacidade instalada da usina térmica é de 15 GWmed e o CVU é $155 \mathrm{R} \$ / \mathrm{MWh}$, o que resulta em um custo com CVU de R\$1.697,25 milhões quando a usina térmica precisa ser acionada. Assim, esses valores de CVaR apresentados na Tabela 13 ocorrem em cenários restritivos, e o CVaR não chega ao valor do custo com o CVU porque o comprador consegue vender energia no mercado de curto prazo nestes cenários, atenuando os custos de acionar a UTE. No modelo proposto, entretanto, o CVaR equivaleria ao custo com o CVU.

No modelo proposto, em momentos de crise hídrica, o comprador não se beneficia mais dos ganhos com a venda do excedente de energia ao PLD. Como os gastos com CVU permanecem e não são mais atenuados pela exposição 
positiva ao PLD nestes cenários, o custo do comprador se torna maior no modelo proposto em períodos de déficit de crise hídrica. Entretanto, com o desconto no preço da energia hídrica por disponibilidade, os custos do comprador em cenários hídricos estáveis são reduzidos no modelo proposto, o que torna o custo total esperado deste agente o mesmo nos dois modelos. 


\section{6 \\ Conclusões e Sugestões para Trabalhos Futuros}

A alternativa de contratação apresentada neste trabalho possibilita a redução da exposição dos geradores aos níveis de geração, por meio da contratação de parte da energia hídrica pela modalidade disponibilidade. As análises indicaram que a aplicação do modelo proposto resulta em um ganho em termos de equivalente certo para os geradores avessos ao risco, evitando perdas não planejadas em cenários de crise hídrica.

Como no modelo proposto o gerador não tem parte da receita exposta aos riscos hidrológicos, assumindo a geração hídrica sempre acima da energia firme, o resultado na CCEE será sempre zero. Assim, em cenários de crise hídrica, os resultados de $\mathrm{CVaR}$ do modelo atual indicaram que o modelo proposto é benéfico ao gerador. Adicionalmente, a comparação destes resultados com a diferença entre a receita proveniente de contratos nos dois modelos ainda aponta o modelo proposto como o mais vantajoso para o gerador. Desta forma, todos os resultados indicam que a troca de modelos é benéfica ao gerador avesso ao risco. Entretanto, em cenários de folga, a receita do gerador proveniente de contratos é reduzida no modelo proposto.

Em relação ao comprador, embora o modelo proposto reduza os custos deste agente em cenários de estabilidade hídrica e os custos esperados sejam equivalentes nos dois modelos, os resultados de CVaR para o comprador considerando o custo com CVU são desfavoráveis no modelo proposto devido à eliminação da exposição positiva ao PLD nos cenários de crise hídrica. No modelo atual, nos cenários de seca, os custos do comprador com as térmicas são atenuados pela venda da energia ao PLD no curto prazo, o que deixa de ocorrer no modelo proposto. Assim, uma sugestão para trabalhos futuros é a criação de um modelo, podendo ser em formato de seguro, que busque atenuar os custos do comprador com a geração de energia térmica em cenários de crise.

Contudo, ainda que o comprador tenha seus custos com CVU atenuados em cenários de crise, o prêmio calculado demonstrou significativa sensibilidade em 
relação aos parâmetros do modelo, os quais podem variar consideravelmente ao longo do tempo. As projeções dos valores de PLD também variaram consideravelmente entre os dois decks de simulação analisados neste estudo. Portanto, um valor único de prêmio definido em contrato por disponibilidade de médio a longo prazo pode distorcer o objetivo do modelo proposto, não sendo a forma mais eficiente para manter os custos esperados do comprador inalterados.

Outra desvantagem do modelo proposto é referente à sua aplicação. Devido ao caráter de reformatação contratual, a aplicabilidade do modelo proposto é reduzida para usinas hidrelétricas com contratos já existentes, em razão da complexidade jurídica de se alterar contratos. Além disso, as usinas hidrelétricas com energia contratada no ACR já estão contempladas com a proposta de seguro oferecida pela ANEEL no final de 2015. Assim, uma recomendação para trabalhos futuros é a adaptação do modelo apresentado em uma proposta alternativa que seja aplicável a hidrelétricas com contratos vigentes, sem a necessidade de alterações contratuais.

Uma sugestão de pesquisa para direcionar as questões de sensibilidade do prêmio e aplicabilidade do modelo é a criação de um mecanismo que permita aos geradores oferecer quantidades de energia flutuantes indexadas ao GSF em troca de quantidades fixas de energia, com o pagamento de um prêmio definido no momento da troca. Este contrato funcionaria como um instrumento de swap e poderia ser negociado tanto no mercado quanto na CCEE, não havendo mais necessidade de alteração de contratos já existentes. A maior dinamicidade deste instrumento em relação aos contratos de longo prazo reduziria as possíveis distorções do prêmio ao longo do tempo e os geradores teriam acesso a uma proteção alternativa aos riscos hidrológicos.

Outra sugestão de estudo é a comparação do modelo apresentado neste trabalho com a proposta de seguro apresentada pela ANEEL, que também tem como objetivo mitigar o risco hidrológico das hidrelétricas. A sugestão é a mensuração dos custos das duas soluções, para uma análise sobre qual modelo seria menos custoso ao gerador e ao comprador, visto que a proposta da ANEEL deve incluir um custo de seguro. Além disso, o estudo poderia incluir uma análise comparativa da eficácia das propostas, de forma a entender qual solução seria mais eficaz na proteção dos riscos hidrológicos para os agentes geradores. 
Por fim, este estudo apresentou um modelo conceitual de uma proposta de mitigação dos riscos hidrológicos do gerador hidrelétrico, com apenas duas usinas e dois cenários, um com déficit e outro com excedente de geração. Portanto, a última sugestão para trabalhos futuros é a análise do modelo proposto em uma modelagem que considere uma maior gama de cenários, utilizando simulações para os níveis de geração hídrica e mais usinas com diferentes CVUs e garantias físicas, de modo que aproxime o modelo do cenário real de comercialização de energia. 
Referências bibliográficas

ASSOCIAÇÃO BRASILEIRA DE DISTRIBUIDORES DE ENERGIA ELÉTRICA (ABRADEE). Glossário do Setor Elétrico. Disponível em: < http://www.abradee.com.br/setor-eletrico/glossario-do-setor-eletrico>. Acesso em: 10 abr. 2017.

AGÊNCIA NACIONAL DE ENERGIA ELÉTRICA (ANEEL). Resolução Normativa $n^{\circ}$ 684, de 11 de Dezembro de 2015. ANEEL. 2015a. Disponível em: <http://www2.aneel.gov.br/aplicacoes/audiencia/arquivo/2015/032/resultado/4850 0.006210-2014-19_resolucao.pdf >. Acesso em: 30 jul. 2016.

Disponível

Nota Técnica no 238/2015-SRG-SRM/ANEEL. ANEEL. $2015 b$. <http://www2.aneel.gov.br/aplicacoes/audiencia/arquivo/2015/032/resultado/nt_2 38_2015-srm-srg_rev2.pdf>. Acesso em: 28 jul. 2016.

Disponível

Nota Técnica no 038/2015-SRG-SRM/ANEEL. ANEEL. 2015c.

<http://www2.aneel.gov.br/aplicacoes/audiencia/arquivo/2015/032/documento/nt 038_-_srg_srm_deslocamento_do_mre-srm_final-18-5-2015-r2.pdf >. Acesso em: 10 abr. 2017.

Energia Assegurada. Cadernos Temáticos da ANEEL. Brasília, 2005.

Disponível em: <http://www2.aneel.gov.br/arquivos/pdf/caderno3capa.pdf>. Acesso em: 10 mai. 2016.

ARFUX, G. A. B. Gerenciamento de riscos na comercialização de energia elétrica com uso de instrumentos derivativos: uma abordagem via teoria de portfólios de Markowitz. Santa Catarina, 2004. Dissertação de Mestrado. Departamento de Engenharia Elétrica, Universidade Federal de Santa Catarina.

ARTZNER, P.; DELBAEN, F.; EBER, J. M. \& HEATH, D. Coherent measures of risk. Mathematical finance, v. 9, n. 3, p. 203-228, 1999.

BARROSO, L. A.; GRANVILLE, S.; TRINKENREICH, J.; PEREIRA, M. V.; LINO, P. Avaliação de Estratégias de Redução de Risco Hidrológico para Empresas com Portfólios Predominantemente Hidroelétricos. XVII Seminário Nacional de Produção e Transmissão de Energia Elétrica. Uberlândia, 2003. 
BRASIL. Decreto $\mathrm{n}^{\circ}$ 6.353, de 16 de Janeiro de 2008. Palácio do Planalto, jan. 2008. Disponível em: <http://www.planalto.gov.br/ccivil_03/_Ato20072010/2008/Decreto/D6353.htm>. Acesso em: 10 mai. 2016.

Decreto n5.163 de 30 de Julho de 2004. Palácio do Planalto. 2004a. Disponível em: <http://www.planalto.gov.br/ccivil_03/_ato20042006/2004/decreto/d5163.HTM>. Acesso em: 10 mai. 2016.

Decreto n5.081 de 14 de Maio de 2004. Palácio do Planalto. 2004b. Disponível em: <http://www.planalto.gov.br/ccivil_03/_ato20042006/2004/decreto/d5081.htm>. Acesso em: 10 mai. 2016.

Lei $\mathrm{n}^{\circ} 10.848$, de 15 de Março de 2004. Palácio do Planalto. 2004c. Disponível em: <http://www.planalto.gov.br/ccivil_03/_ato20042006/2004/lei/110.848.htm>. Acesso em: 10 mai. 2016.

BRITO, M. C. T. Análise da Repactuação do Risco Hidrológico das Usinas Hidrelétricas Participantes do Mecanismo de Realocação de Energia. Rio de Janeiro, 2016. Tese de Doutorado. COPPE, Universidade Federal do Rio de Janeiro.

CAMARGO, I. Análise do processo de reestruturação do setor elétrico brasileiro. Revista Brasileira de Energia, Vol. 11, n², 2005.

CÂMARA DE COMERCIALIZAÇÃO DE ENERGIA ELÉTRICA (CCEE). Preços Médios. Disponível em: $<$ https://www.ccee.org.br/portal/faces/pages_publico/o-quefazemos/como_ccee_atua/precos/precos_medios?_afrLoop=91964334363565> Acesso em: 04 jan. 2017.

. CCEE: Redução da carga de energia contribui para queda do PLD nos últimos meses. CCEE, jan. 2016. Disponível em: <https://www.ccee.org.br>. Acesso em: 08 set. 2016.

Liquidação Financeira no MCP de energia elétrica movimenta R \$1,9 bilhão. CCEE, out. 2015. Disponível em: <https://www.ccee.org.br>. Acesso em: 04 jan. 2017.

InfoMercado Semanal. No02 - N $^{\mathrm{a}}$ semana de setembro de 2014. Disponível em: <https://www.ccee.org.br.> Acesso em: 05 set. 2016.

Regras de Comercialização. Mecanismo de Realocação de Energia. Versão 2013.1.0, 2013. Disponível em: <www.ccee.org.br/ccee/documentos/CCEE_076159>. Acesso em: 05 set. 2016. 
. Preço de Liquidação de Diferenças. Regras de Comercialização <http://www2.aneel.gov.br/aplicacoes/audiencia/ arquivo/2009/035/documento/modulo_04_garantia_fisica_uhes.pdf $>$. Acesso em: 05 jan. 2017.

. Regras de Comercialização. Contabilização. Módulo 4 - Garantias

Físicas. $\quad 2010$ Versão Disponível em: < http://www2.aneel.gov.br/aplicacoes/audiencia/arquivo/2009/035/documento/mod ulo_04_garantia_fisica_uhes.pdf>. Acesso em: 08 mai. 2016.

CASTRO, N. J.; BRANDÃO, R. O Risco Financeiro de um Período Seco Prolongado para o Setor Elétrico Brasileiro. Texto de Discussão do Setor Elétrico, $\mathrm{n}^{\circ}$ 17. GESEL, Rio de Janeiro, 2010.

CENTRO DE PESQUISA DE ENERGIA ELÉTRICA (CEPEL). Projeto Newave: Modelo Estratégico de Geração Hidrotérmica a Subsistemas Equivalentes. Manual do Usuário. Versão 17.5.3, 2013.

COSTA, R. C. D.; PIEROBON, E. C. Leilão de energia nova: análise da sistemática e dos resultados. BNDES Setorial. Rio de Janeiro, n. 27, p. 39-57, 2008 .

DAMODARAN, A. Gestão Estratégica do Risco: uma referência para a tomada de riscos empresariais. Bookman, 2009.

DAVID, P. A. M-S; BARROSO, L. A; GRANVILlE, S.; FILHO, A. V. Contratação e Aversão ao Risco no Despacho Competitivo da Geração. XVII Seminário Nacional de Produção e Transmissão de Energia Elétrica. Uberlândia, 2003.

DOMINGUES, E. G. Análise de risco para otimizar carteiras de ativos físicos em geração de energia elétrica. Itajubá, 2003. Tese de Doutorado. Departamento de Engenharia Elétrica, Universidade Federal de Itajubá.

ELTON, E.J; GRUBER, M. J.; BROWN, S. J.; GOETZMANN, W. N. Modern Portfolio Theory and Investment Analysis. 9 $9^{a}$ Edição. John Wiley \& Sons, 2014.

EMPRESA DE PESQUISA ENERGÉTICA (EPE). Balanço Energético Nacional 2016: Ano base 2015. Rio de Janeiro, 2016. Disponível em: <https://ben.epe.gov.br/>. Acesso em: 20 out. 2016.

Balanço Energético Nacional 2015: Ano base 2014. Rio de Janeiro, 2015. Disponível em: <https://ben.epe.gov.br/>. Acesso em: 20 out. 2016.

HULL, J. C. Opções, Futuros e Outros Derivativos. 9ª Edição. Bookman, 2016. 
JORION, P. Value at Risk. 2 ${ }^{\text {a }}$ Edição. Bolsa de Mercadoria \& Futuros, 2003.

KEENEY, L. R.; RAIFFA; H. Decisions with Multiple Objectives: Preferences and Value Tradeoffs. Cambridge University Press, 1993.

SÁNCHEZ, J. C. M. Estudo da Negociação de Contratos Bilaterais de Energia em Sistemas Predominantemente Hidráulicos. Brasilia, 2008. Tese de Doutorado. Departamento de Engenharia Elétrica, Universidade de Brasilia.

SOUZA, F. C.; LEGEY, L.F.L. Brazilian electricity market structure and risk management tools. In: Power and Energy Society General MeetingConversion and Delivery of Electrical Energy in the 21st Century, 2008 IEEE. IEEE, 2008. p. 1-8.

MINISTÉRIO DE MINAS E ENERGIA (MME); EMPRESA DE PESQUISA ENERGÉTICA (EPE). Plano Decenal de Expansão de Energia 2024. Brasilia, $2015 . \quad$ Disponível em: <http://www.epe.gov.br/PDEE/Relat\%C3\%B3rio\%20Final\%20do\%20PDE\%202 024.pdf $>$. Acesso em: 08 jul. 2016.

Plano Decenal de Expansão de Energia 2022. Brasilia, 2013.

Disponível em: <http://www.epe.gov.br/PDEE/Relat\%C3\%B3rio\%20Final\%20do\%20PDE\%202 022.pdf $>$. Acesso em: 12 jul. 2016.

Metodologia de Cálculo da Garantia Física das Usinas. 2008. Disponível em: <http://www.epe.gov.br/geracao/Documents/Estudos_26/NT\%20$\% 20$ metodologia\%20de\%20c\%C3\%A1lculo\%20da\%20GF\%20para\%20novas $\% 2$ Ousinas.pdf>. Acesso em: 12 set. 2016

OPERADOR NACIONAL DO SISTEMA (ONS). O ONS - Planejamento Estratégico. 2016a. Disponível em: <http://www.ons.org.br/institucional_linguas/orientacoes_estrategicas.aspx > . Acesso em: 22 jul. 2016.

O que é o SIN - Sistema Interligado Nacional. 2016b. Disponível em: <http://www.ons.org.br/conheca_sistema/o_que_e_sin.aspx.> Acesso em: 22 jul. 2016.

PEREIRA, M. V.; BARROSO, L. A.; ROSENBLATT, J. Supply adequacy in the Brazilian power market. In: Power Engineering Society General Meeting, 2004. IEEE. IEEE, 2004. p. 1016-1021.

RIBEIRO, R. C. Avaliação dos riscos de liquidação de energia associados à sazonalização de garantia física de pequenas centrais hidrelétricas. Brasilia, 
2012. Dissertação de Mestrado. Departamento de Engenharia Elétrica, Universidade de Brasilia.

ROCKAFELLAR, R. T.; URYASEV, S.. Conditional value-at-risk for general loss distributions. Journal of banking \& finance, v. 26, n. 7, p. 1443-1471, 2002.

STREET, A. Equivalente Certo e Medidas de Risco em Decisões de Comercialização de Energia Elétrica. Rio de Janeiro, 2008. Tese de Doutorado. Departamento de Engenharia Elétrica, PUC-Rio.

VON NEUMANN, J.; MORGENSTERN, O. Theory of games and economic behavior. Princeton university press, 2007. 